\title{
A methodological framework to relate the earthquake-induced frequency reduction to structural damage in masonry buildings
}

\author{
Daniele Sivori $^{1}$ (D) $\cdot$ Serena Cattari ${ }^{1}$ (ID $\cdot$ Marco Lepidi $^{1}$ (D)
}

Received: 7 October 2021 / Accepted: 29 January 2022 / Published online: 18 February 2022

(c) The Author(s) 2022

\begin{abstract}
The diffusion of seismic structural health monitoring systems, evaluating the dynamic response of engineering structures to earthquakes, is growing significantly among strategic buildings. The increasing availability of valuable vibration data is being backed by continuously evolving techniques for analysing and assessing structural health and damage. Within this framework, the paper proposes a novel model-driven vibration-based methodology to support the assessment of the damage level in masonry buildings hit by earthquakes. The leading idea is to exploit, in the pre-event phase, synthetic equivalent-frame modelling and nonlinear dynamic analyses to systematically relate the gradual reduction of natural frequencies to increasing levels of structural damage. The resulting behavioural chart (seismic chart) of the building, constructed by employing computational tools and robustly defined on a statistical base, may provide the theoretical expectation to ascertain a certain level of seismic damage, based on the decrease in vibration frequency experimentally identified in the post-event phase. The methodology is firstly formalized, integrating common identification techniques with a novel damage grade estimation procedure, and finally exemplified for a monitored strategic masonry building damaged by the 2016-2017 Central Italy earthquake sequence. The outcomes of this application confirm the operational validity of the methodology, which can be intended as effective support for the decision-making process regarding structural usability and safety in the post-earthquake scenario.
\end{abstract}

Keywords Structural monitoring $\cdot$ Seismic damage $\cdot$ Masonry buildings $\cdot$ Equivalent frame $\cdot$ Nonlinear dynamic analyses $\cdot$ Experimental modal analysis

Daniele Sivori

daniele.sivori@dicca.unige.it

Serena Cattari

serena.cattari@unige.it

Marco Lepidi

marco.lepidi@unige.it

1 Department of Civil, Chemical and Environmental Engineering (DICCA), University of Genoa, Via Montallegro 1, 16145 Genoa, Italy 


\section{Introduction}

The relationship between modal properties and structural integrity of dynamical systems constitutes one of the founding pillars of modern vibration-based structural health monitoring. In the civil engineering field, the renowned interest in the assessment and conservation of the built heritage - alongside the technological and computational advancements of the last decades - is driving the scientific community towards the development of innovative vibration-based assessment solutions (García-Macías and Ubertini 2020).

Within this challenging scenario, the main objective of this paper is to deepen the knowledge regarding natural frequency variations exhibited by masonry buildings damaged by earthquakes, highlighting how such information could be profitably integrated by mechanical modelling to support the evaluation of structural damage in post-earthquake scenarios. At the present day, the development of vibration-based damage assessment methodologies is being led by the research field (an overview on various areas of application is reported in Limongelli and Çelebi 2019). The practical viability of the available tools is still debated, so that the endorsement by non-academic stakeholders is encountering a certain resistance. As a consequence, the capillary employment of monitoring systems in civil structures is not yet systematic, usually employed for the condition assessment of relevant historical and monumental architectures as well as structures and infrastructures of strategic importance: a large-scale diffusion appears a promising, but medium-tolong term, perspective. Moreover, even if early-warning systems are becoming more and more common, still few are the applications exploiting monitoring systems to support the public management of the post-earthquake emergency phase (Dolce et al. 2017a, 2019a; Spina et al. 2019, 2021; Acunzo et al. 2022).

Based on these motivations, the proposal of this paper is addressed at the quick postearthquake vibration-based damage assessment of strategic masonry buildings, when dynamically monitored as part of local or national seismic mitigation strategies. Given the fundamental role played by strategic structures during the seismic emergency in managing the live response phase and the post-earthquake recovery phase, quick strategies to support the assessment of their damage state, usability and residual functionality could benefit from the proposed integration of vibration measurements and mechanical modelling. Such an approach could provide precious support to the decision-making process, today strongly relying on the expert engineering judgement of actual damage observation as a result of on-site inspections (Dolce and Di Bucci 2014; Di Ludovico et al. 2019a, b, 2021). The leading idea is to employ an Equivalent Frame (EF) model of the masonry building, calibrated based on operational vibration data, to simulate the nonlinear response of the structure for increasing intensities of the seismic event. Such a modelling technique, among other possible choices suited for masonry structures (for a comprehensive review of the state-of-the-art see D'Altri et al. 2020), is selected for his computational efficiency in performing large sets of nonlinear dynamic analyses. This approach allows relating the simulated damage level to the variation of modal properties, synthesized in the form of a natural frequency reduction-damage seismic chart to be built during peacetime. After the earthquake, exploiting an inverse approach, experimentally identified variations in the modal characteristic of the damaged structure can provide, through the seismic chart, an expectation of the occurred damage level. Moreover, as part of the comprehensive set of results provided by physics-based models, quantitative estimates of the residual capacity of the building can be usefully employed to orient the decisions in case of after-shocks (Reuland et al. 2019; Di Ludovico et al. 2019c). The issue is particularly relevant in the case 
of masonry buildings which, as testified by recent earthquakes (Sextos et al. 2018), may exhibit an abrupt increase of damage following multiple seismic events due to their rapidly reducing residual capacity and pronounced softening phase.

Section 2 gives a synthetic introduction of the current scientific knowledge on the matter, exploring some recent literature examples which highlight issues and challenges in the study of frequency-variation phenomena for masonry buildings. Section 3 proposes a general methodology to simulate and identify the earthquake-induced reduction of natural frequency following structural damage, by reproducing the seismic response of monitored masonry buildings through nonlinear dynamic analyses on dynamically-calibrated EF models. The focus is put on the evaluation of the building damage grade from the simulation results in a framework coherent with the European Macroseismic Scale (EMS-98, Grünthal 1998), starting from the interpretation of damage in the structural element up to that of the whole building. The relationship between frequency reduction and structural damage is embodied by fragility-like curves, the heart of this proposal. Section 4 investigates the problem from an experimental point of view, analysing vibration data from a seismic-monitored masonry building in Central Italy, the Pizzoli town hall, and investigating the relationship between frequency reduction and structural damage caused by recent earthquakes. The case-study structure is dynamically monitored by the Italian Structural Monitoring Network (Dolce et al. 2017a) managed by the Italian Department of Civil Protection (DPC). Moreover, its seismic response to the 2016-2017 Central Italy earthquake sequence has been extensively studied by different research groups (Spina et al. 2019; Cattari et al. 2019; Miraglia et al. 2020; Degli Abbati et al. 2021). Section 5 practically exemplifies the methodology, developing the building frequency reduction-damage seismic chart to support the damage assessment and decisional process in the post-earthquake scenario. Section 6 , finally, identifies the objectives achieved by the research and the potential improvements to be addressed in future works.

\section{Natural frequency reduction in civil structures hit by earthquakes: a focus on damaged masonry buildings}

In the field of earthquake engineering, the use of dynamic measurements of structural vibrations-including both the ambient response to the environmental excitation and the seismic response to earthquake excitation-is being widely recognized as a feasible tool to identify the modal properties of existing structures (Luş et al. 1999; Guéguen et al. 2014; Gattulli et al. 2016; Ewins 2016). This experimental technique, thanks to its non-destructive and non-invasive characteristics, is today increasingly employed to support the seismic analysis of existing structures. The knowledge of the experimental modal parameters, which reflects the actual operative condition of the structure, plays a primary role in the formulation (Michel et al. 2008; Spina et al. 2019), validation and updating (Mottershead and Friswell 1993; De Sortis et al. 2005; Snoj et al. 2013; Foti et al. 2014; Sivori et al. 2020; Cattari et al. 2021b; Degli Abbati et al. 2021; Ponte et al. 2021) of experimental and mechanical models, significantly improving the robustness of seismic predictions. The employment of ambient vibrations, in particular, is extremely valuable for structural health assessment, often in the form of continuous monitoring systems. Such an approach allows a data-based evaluation of the structural conditions, which tends to be limited to damage detection and/or localization, backed by a more robust model-driven quantification (Carden and Fanning 2004; Brownjohn et al. 2011). 
The approach to damage identification is typically comparative, so that detected changes in the vibration properties with respect to the baseline- undamaged - state are correlated to expected changes in structural integrity, taking into account several potential originating sources. Among the possible damage-sensitive features, the founding idea is that modal parameters, in particular natural frequencies, depend in a predictable way to changes in structural stiffness and can thus be considered as meaningful damage indicators (Doebling et al. 1996; Salawu 1997; Doebling et al. 1998; Morassi and Vestroni 2008). The main trends of the literature tackle damage estimation through direct data-driven approaches, proposing criteria relying on the sole variation of the experimentally identified modal parameters. Further insights into structural behaviour can be gained by mechanical-based modelling (see for example Kita et al. 2020), in which ensuring both the representativeness and efficiency of the formulation constitutes one of the main challenges. The paper will focus on this second possibility. The following discussion is not intended to present a comprehensive review of the state-of-the-art on the topic. Conversely, the objective is to highlight some recent and relevant results in the vibration-based estimation of seismic damage in existing masonry buildings, pointing out some issues and knowledge gaps that motivates the development of this research.

As highlighted by several contributions of the literature, variations in the natural frequencies of vibration of buildings are observed both during and after earthquakes (Bodin et al. 2012; Vidal et al. 2014), even in absence of structural damage (Çelebi 2007). To sum up these recent findings, frequency variations can be regarded as amplitude-dependent phenomena, composed of a transient-reversible — contribution and a permanent-irreversible - contribution. The first, observed during the seismic motion, is related to reversible material and geometrical nonlinearities, pertaining both to the soil and the structure and generally caused by their mutual dynamic interaction (Todorovska 2009). The structural nonlinearities can be traced back to, among other possibilities, temporary micro-cracking and sliding effects in the building materials. The so-called frequency wander (Clinton et al. 2006) is surely observed in the case of strong earthquakes, and also during weak forced vibrations and seismic motions (Spina and Lamonaca 1998; Ceravolo et al. 2017) where it may be governed by the frequency characteristics of the input motion (Michel and Guéguen 2010). Indeed, if no structural damage occurs, the frequency shift gradually vanishes in time, so that the pre-seismic values of the natural frequencies are completely recovered. Conversely, variations of natural frequencies observed after the seismic eventreferred to as post-seismic reduction and those of primary interest in the paper-can reflect a permanent effect of structural damage. It has been recently remarked, moreover, that a quasi-permanent part of the frequency reduction or decay linked to material strain (Astorga et al. 2018; Astorga and Guéguen 2020a, b) can be slowly recovered over time after the earthquake, and how such a recovery can be employed as a proxy for the structural health assessment (Astorga et al. 2019; Guéguen et al. 2020). The slow recovery process, the effect of environmental conditions such as temperature, humidity, groundwater level, excitation level and the role of the foundation soil make a robust identification of the postseismic frequency variations a hard task.

These are the relationships and issues that modern health-monitoring applications are facing. From this background, starting from damage detection up to its quantification, the research community undertook the development of non-destructive evaluation techniques (Picozzi et al. 2010; Ponzo et al. 2010) to be employed in structural health monitoring applications and post-earthquake assessments. Most of the investigations, however, deal with the study of reinforced concrete structures. In the case of masonry, vibration-based damage assessment applications are more frequent in the health monitoring of monumental 
structures such as towers and palaces (Gentile and Saisi 2007; Cabboi et al. 2017; GarcíaMacías et al. 2020; Venanzi et al. 2020; Kita et al. 2021), whereas only a secondary interest is addressed to ordinary and strategic masonry buildings.

Michel et al. (2011) studied the natural frequency and damping evolution of low-rise brick masonry buildings by means of laboratory pseudo-dynamic tests on scaled models and in situ forced vibration tests on full-scale buildings. The research, exploiting both input-output and output-only identification techniques, shows how relative frequency variations are well described by the initial frequency and maximum vibration amplitudeinterstorey drift ratio or simply interstorey drift-whereas the initial damage state seems not to be affecting the frequency degradation path. Up to a $20 \%$ elastic frequency shift is observed in absence of structural damage, around 33\% at yield and up to $80 \%$ total inelastic frequency reduction at the ultimate state. The damping ratio is observed to slightly increase till moderate damage state and dramatically afterwards, even though its variations seem not to be satisfyingly described by the maximum interstorey drift. Kouris et al. (2019) exploited consecutive full-scale shaking table tests with increasing levels of amplitude and induced structural damage to identify rapid variations in natural frequencies and damping ratios, with gradual changes in mode shapes. Results from output-only techniques in the frequency domain and input-output techniques in the time domain are in good agreement, showing interesting frequency reductions up to $20 \%$ in absence of evident structural damage. Martakis et al. (2021) observed a similar amplitude-dependent nonlinear behaviour in a real masonry building under demolition. Ceravolo et al. (2017) pointed out how modal models deriving from linear identification of concrete and masonry buildings excited by small-to-medium ground motions show a significant amplitude dependence, in which frequency and damping wandering is observed following different shaking amplitudes. In particular, in the absence of structural damage, the amplitude dependence is linear in the logarithmic plane, decreasing for frequencies and increasing for damping ratios. Spina et al. (2019) observed a co-seismic decrease in the fundamental frequency of a masonry building monitored by the Italian Structural Monitoring Network (Dolce et al. 2017a) and hit by the Italian Central Italy earthquake sequence of 2016, the Pizzoli town hall building. The time-frequency analysis of data highlights the nonlinear relationship between vibration frequency and the maximum roof drift, which is shown to have a strong influence on the reliability of seismic predictions already for low levels of seismic intensity.

On this solid basis, the following Sections will embrace the identification and simulation of seismic-induced frequency variations in damaged masonry buildings, proposing a methodological framework taking advantage of the complementarity between experimental techniques and computational simulations.

\section{A frequency reduction-damage seismic chart of monitored masonry buildings based on the Equivalent Frame approach}

\subsection{Methodology}

In this Section, a novel strategy to simulate the decrease of natural frequency in masonry buildings damaged by earthquakes is proposed. The methodology exploits the integration between experimental vibration measurements in the form of permanent monitoring systems and computational modelling for nonlinear simulations. Such an approach, which could be referred to as model-driven and data-based, aims at building a seismic chart of the 
structure to support the decisional processes in the post-earthquake scenario-regarding the assessment of the building short-term usability and safety, as well as the forecast of the long-term structural behaviour during aftershocks. The focus is put on the simulation and identification of the permanent post-seismic natural frequency reduction, to define the relationship with the corresponding level of structural damage. The methodology is detailed in the following with reference to the logical flow chart reported in Fig. 1.

The initial step (task a) deals with the experimental identification of the relevant modal parameters of the building (in this case, fundamental frequencies and mode shapes) from vibration measurements acquired in the pre-earthquake operational conditions, fixing the undamaged - or baseline-reference state. The modal identification, indeed, can be achieved by exploiting any output-only (or equivalently input-output) technique (Reynders 2012). The sources of aleatory uncertainties, in this phase, can be traced back to experimental variability, for example to varying environmental conditions or unaccounted excitations - such as unmeasured frequency-localized inputs. Possible systematics-depending on the sensor's sensitivity and dynamic range, instrumental noise, signal conditioning,

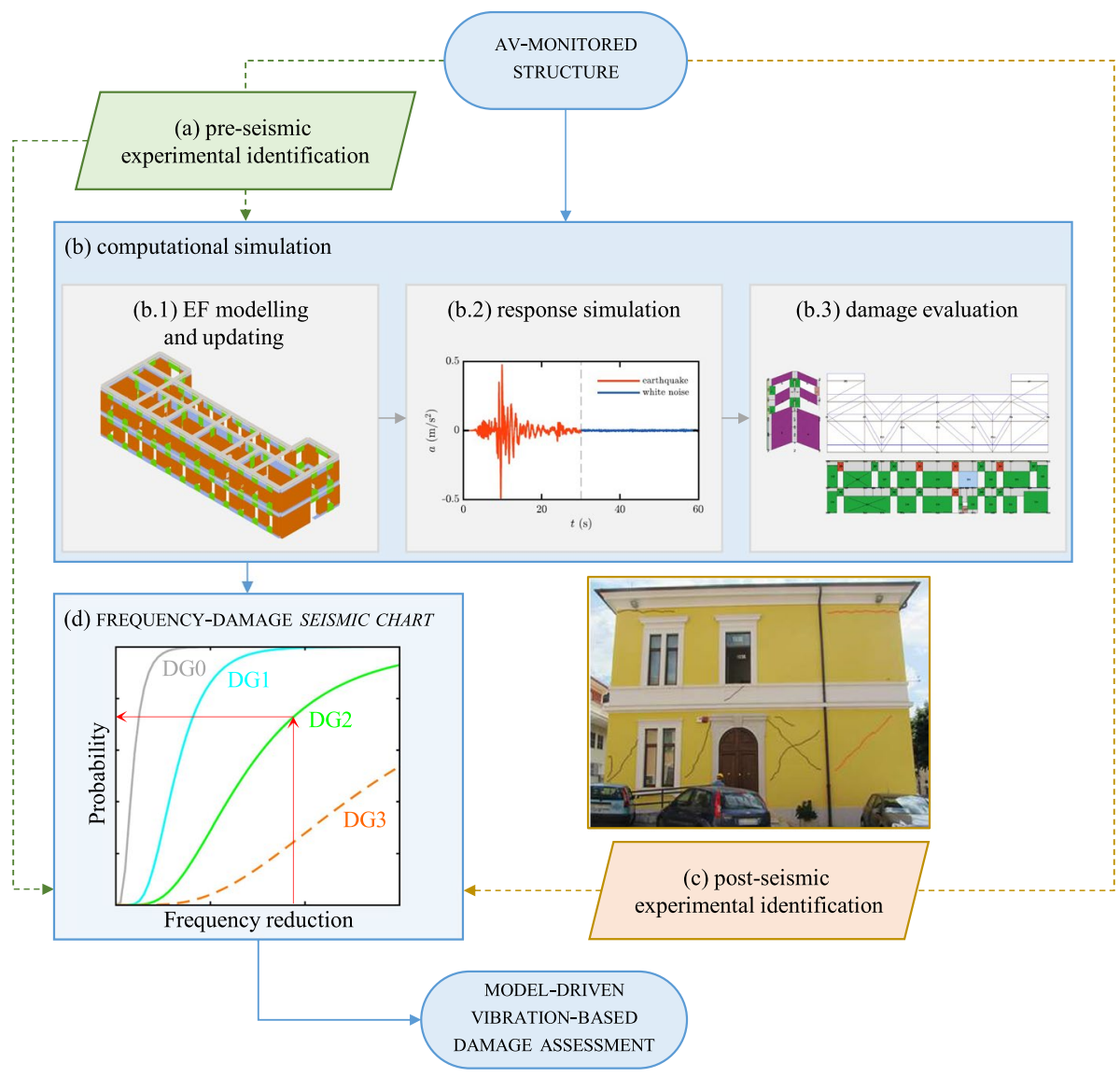

Fig. 1 Methodological flow to develop the EF model-driven, vibration-based seismic chart of monitored masonry buildings, relating the natural frequency reduction experimentally identified after the earthquake with the expected structural damage grade 
digitization and storage, phase synchronization, measurements layout, etc.-should be carefully accounted for, not to undermine the reliability of the identified modal parameters. In the case of complex structures, a sparse layout of sensors can lead to spatial aliasing, effectively preventing the reliable identification of mode shapes (employed for mode-pairing in the comparison with the damage state, task d).

The computational simulation (task b) calls for the selection of the appropriate structural modelling technique, as well as of the corresponding seismic analysis framework. A compromise between fidelity and simplification should be sought, so that the competing requirements of representativeness and synthesis are well-balanced. Among other possible modelling approaches, in the case of masonry buildings, the Equivalent Frame (EF) formulation (subtask b.1) appears a suited choice. Commonly, EF models have lower computationally requirements than classical Finite Element (FE) ones, notwithstanding their good capability in reproducing the seismic response of masonry buildings (in particular of those with a regular openings layout, see Cattari et al. 2021a, b; Brunelli et al. 2021). Current techniques of modal and structural updating can be employed to calibrate the elastic mechanical properties of the model and to narrow other possible modelling uncertainties of aleatory and epistemic nature (subtask b.1). This ensures that the computational dynamics reproduces with the maximal possible accuracy the experimental behaviour identified from the ambient response of the undamaged structure.

Concerning the selection of the suitable seismic analysis framework, the development of the seismic chart requires the simulation of the nonlinear response of the structure to increasing intensities of the seismic excitation, with the purpose of inducing and characterizing states of increasing structural damage. Nonlinear dynamic analyses are to be preferred over static ones, given the higher accuracy in reproducing the nonstationary seismic response, resulting in a more accurate prediction of damage severity and diffusion (Lagomarsino and Cattari 2015b). The damage characterization can be achieved by interpreting the numerical results, establishing a statistical relationship between a quantifiable parameter-representative of the seismic response, an Engineering Demand Parameter (EDP) and the simulated level of global damage. This statistical relationship can be recovered by employing the techniques employed in the probabilistic investigation of structural fragility. There are several nonlinear dynamic analysis procedures available in the literature to characterize the relationship between EDPs and Intensity Measures (IMs) of the recorded ground motions, such as the Incremental Dynamic Analysis (IDA, Vamvatsikos and Cornell 2002), the Multiple-Stripe Analysis (MSA, Jalayer and Cornell 2009), the Cloud Method (Bazzurro et al. 1998; Jalayer et al. 2015, 2017). It should be clarified that, in this context, the investigation is aimed at the characterization of the direct relationship between two structural response measures - in this specific case, frequency reduction and structural damage - rather than between seismic intensity and structural response. Nonetheless, the selection of the seismic ground motion could benefit from specific disaggregation studies (Iervolino et al. 2011).

The choice of the suited seismic analysis framework determines the criteria for the selection and processing of the seismic records-involving the postponement of a lowintensity ambient excitation source to the earthquake signal (subtask b.2i) - and the suitable solution algorithm. To guarantee a reliable post-seismic identification, the postponed input noise should be (i) bandpass white in the range of natural frequencies to be excited and monitored, (ii) low-amplitude, to avoid a nonlinear response, (iii) long enough to guarantee a satisfying frequency resolution, (iv) high-frequency sampled (i.e. short time step) to improve the accuracy of the time-domain solution algorithm. Technical considerations regarding these points are reported in Sect. 5.1. Other computationally-efficient strategies 
avoiding the addition of the ambient noise part, such as those based on the update of stiffness properties in damaged elements, could be employed as well.

In the post-processing phase, the EDPs representative of the structural response are estimated. Among the others, the natural frequency of the damaged structure can be estimated by means of output-only modal identification of the pseudo-experimental ambient response of the structure. The relation between the frequency decrease-with respect to the baseline model - and the expected global level of damage on the structure (subtask b.3) can be investigated with reference to empirical metrics, such as the EMS-98 (Grünthal 1998) adopted in the macroseismic post-earthquake assessment. The following Sections, in this respect, propose a model-based damage assessment framework for masonry building, aimed at the estimation of the damage grade from the results of the EF-based nonlinear dynamic analyses. Such a goal is achieved by interpreting the seriousness and extension of the damage at different scales (Sect. 3.3).

Finally, once the frequency reduction-damage relationship has been characterized, any experimentally detected decrease in the fundamental frequency of the actual structure (task c) imputable to earthquake-induced structural damage provides an expectation of the damage grade of the structure through the seismic chart (task d). It is understood that, if known, the effect of other external factors potentially affecting the behaviour of the structure-such as temperature variations, see Sect. 4.2-should be properly accounted for in the comparison of the baseline-damaged states (task a, task c).

\subsection{A multiscale damage assessment framework for masonry buildings}

The employment of experimental modal parameters as sensitive indicators of structural integrity is a well-known and understood concept in the Structural Health Monitoring (SHM) field (see the discussion of Sect. 2). In particular, in the past two decades, several studies have been conducted regarding the detection of structural damage on civil infrastructures (Farrar et al. 2001; Carden and Fanning 2004). For what concerns buildings, even though new non-contact technologies such as computer vision (Feng and Feng 2018; Rezaie et al. 2020a) and radar interferometry (Luzi et al. 2017) are becoming more and more common, most applications are still relying on the use of vibration measurements acquired by physical sensors.

Nevertheless, vast room for improvements is still present concerning damage quantification-to relate a measured variation in the modal properties of the structure to the expected level of occurred structural damage - which appears a more challenging task, at least for complex structures such as buildings. This knowledge could be extremely valuable for monitored buildings, in order to support the assessment of damage in the post-earthquake scenario. A forward step in this direction can be pursued by numerical simulations and nonlinear modelling. Among the other possibilities, the equivalent-frame modelling approach seems a straightforward choice, allowing the execution of multiple runs of nonlinear analyses (in the static and dynamic regimes) on quite detailed models with a reasonable computational effort. It is not straightforward, however, to interpret the complexity of the simulated response in a meaningful and synthetic way (Lagomarsino and Cattari 2015b).

For this purpose, it is useful to rely on the definitions of observational Damage Grades (DGs) commonly adopted in macroseismic post-earthquake assessment, such as those proposed in the European Macroseismic Scale (EMS-98, Grünthal 1998). Damage grades have an unmeasurable but empirical nature, closely representative of the physical evolution 
of structural damage. They can be easily related to the Performance Level (PL) adopted in the modern seismic performance-based design and, more importantly, they assume a relevant role in the decisional processes regarding the safety of structures in post-earthquake scenarios. The pursued relationship between earthquake-induced fundamental frequency reduction and corresponding level of global damage aims, thus, at providing an alternative vibration-based experimentally identifiable damage metric.

Establishing a robust relationship between the damage observed at the local scale (i.e. severity and diffusion in various components of the building, such as walls, floors and roofing systems, stairs, non-structural elements) and the one at the global scale (understood, in this discussion, as the damage grades proposed in the EMS-98) is still an open problem in the literature. The issue emerges in the interpretation of the observed structural damage in existing structures hit by earthquakes. This is testified by the several damage conversion rules proposed in the literature, employed to develop fragility curves according to empirical or heuristic approaches (for masonry buildings Dolce et al. 2017b, 2019b; Rota et al. 2008; Rosti et al. 2020; Lagomarsino et al. 2021). For what concerns fragility curves based on a numerical approach, a common choice is to refer to the attainment of conventional thresholds by specific Engineering Demand Parameters (EDPs). The latter usually consist of measurable quantities, such as the roof drift, the maximum interstorey drift or the peak floor acceleration (Cattari et al. 2018; Ricci et al. 2018).

Indeed, the amount of results produced by nonlinear dynamic analyses gives a comprehensive picture of the building response, but its proper processing - to determine the attainment of a given damage or performance level-is not straightforward. A state-ofthe-art analysis of this topic is reported in Lagomarsino and Cattari (2015b). Generally, a limitation emerges in the adoption of a single criterion, which seems unreliable to detect all possible failure mechanisms (Mouyiannou et al. 2014; Lagomarsino and Cattari 2015a). To overcome this problem, a multiscale approach for defining DGs in the case of historical masonry building has been originally proposed in the framework of the PERPETUATE project (Lagomarsino and Cattari 2015a). The leading idea is to combine different criteria and checks at various scales relevant for the seismic response of the building, i.e. structural elements scale (local damage), architectural elements scale (damage in macroelements), building global scale. Accordingly, a coherent approach is applied to define the DGs in the case of both nonlinear static analyses, where the EDP is represented by the displacement reached on the pushover curve, and nonlinear dynamic analyses, to which the method has been extended (Lagomarsino and Cattari 2015b). The multiscale approach has been further developed replacing the adoption of interstorey drift thresholds at the wall scale (Marino et al. 2019). This allows overcoming the conventional definition of inter-floor drift thresholds, which are not suited to consider all the damage mechanisms exhibited by structural elements of different slenderness.

The recent proposal of Cattari and Angiolilli (2022) tackles the interpretation of the observed seismic damage in masonry buildings according to the EMS-98 metric, employing analytical criteria at different scales. In particular, the global damage grade is assessed based on the damage gravity at the wall scale, recovered in turn from the scale of structural elements (Fig. 2). This approach is consistently applicable to the results of numerical simulations as well, making explicit the relationship between the analytical criteria and the physical significance of damage diffusion. The pursued approach-already proposed in the literature, but for other purposes (Giovinazzi and Lagomarsino 2004; Lagomarsino and Giovinazzi 2006) — requires to, first, provide a numerical interpretation of the linguistic description of the damage grades of buildings proposed by the EMS-98, and second, to associate to such metric the damage exhibited by the building (alternatively simulated by 


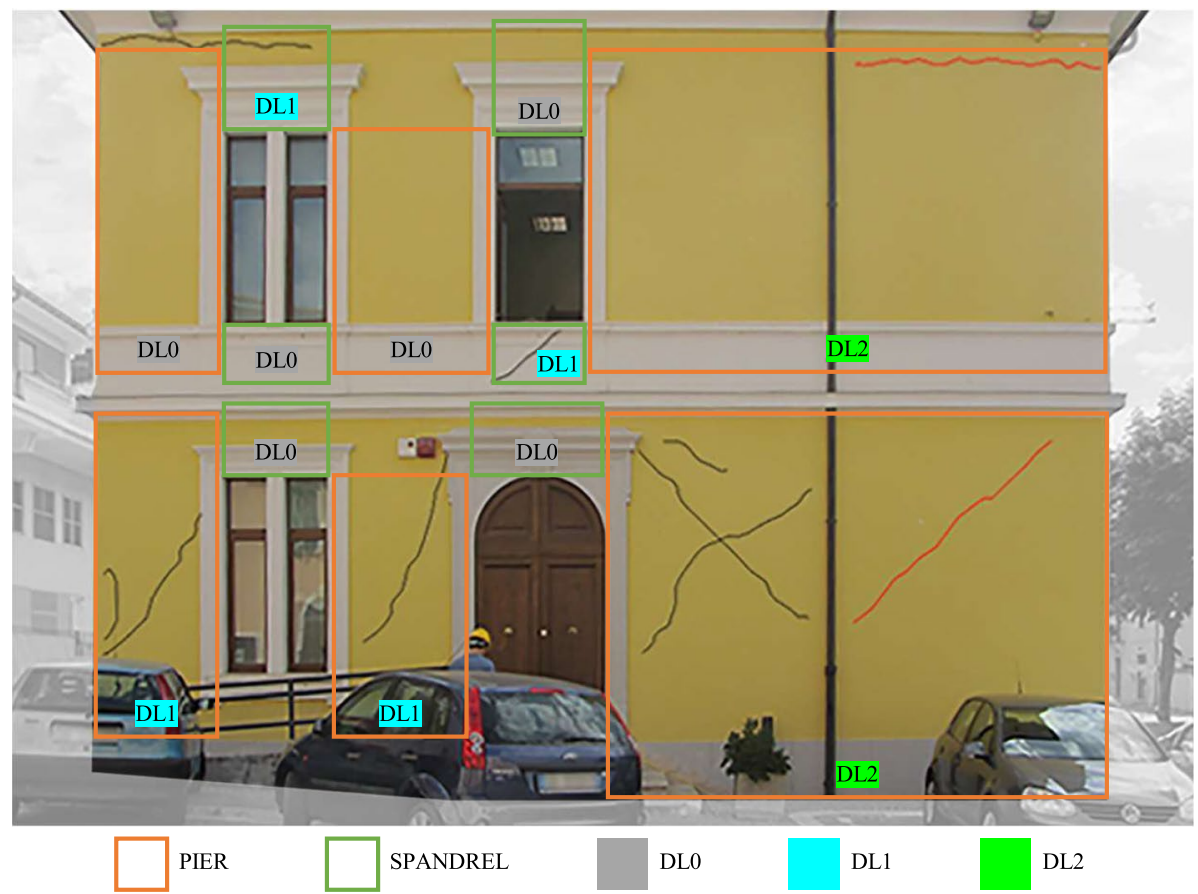

Fig. 2 Assignment of damage levels to structural elements based on the observation of actual damage exhibited by masonry panels, exemplified for a perimeter wall of the Pizzoli town hall building as surveyed after the Central Italy earthquake sequence of 2016-2017 (Sect. 4.3). Black lines represent superficial cracks whereas red lines highlight through-cracks. The average damage level of the wall can be evaluated based on the gravity and extension of damage observed at the structural element scale (Sect. 3.3)

the structural model) at different scales. The five damage grades for masonry buildings are defined - from a quantitative point of view - by a quite vague description of the expected damage and its extension on the building (left side of Table 1). For the first time, in the following, the procedure proposed by Cattari and Angiolilli (2022) and slightly revised in this paper is extensively applied to the results of nonlinear dynamic analyses on the EF model, coupling the wall-scale criteria with controls at the global scale related to the residual capacity of the building (Sect. 3.3).

\subsection{Evaluation of the EMS-98 global damage grade from nonlinear dynamic analyses}

The discussion is focused on existing and historical masonry buildings characterized by a boxlike seismic behaviour, for which a three-dimensional equivalent frame idealization is an appropriate modelling choice. Under the common assumptions of this approach, the assessment of damage refers to the global response of the building as the result of the inplane behaviour of the bearing walls, ruling out the possible activation of local mechanisms. The simulation and assessment of damage to other structural elements (stairs, storey diaphragms, roofing systems) are, in this phase, postponed to future developments of the research. The possible damaging of nonstructural elements (infill walls, false ceilings) is 
neglected, being understood that these elements can have a primary influence on the performance levels of some structural typologies (i.e. infills for the structural operativity of reinforced concrete buildings), even though that influence is still quite limited for masonry buildings (Ottonelli et al. 2020).

The damage assessment proposed in this Section aims at the global evaluation of the EMS-98 damage from the results of nonlinear dynamic analyses. The pursued multiscale approach, in particular, starts from the interpretation of damage at the structural element scale up to the assignment of a damage grade at the global scale. At the element scale, i.e. that of masonry panels, the piecewise linear constitutive laws adopted in the simulations (Sect. 5), representative of the empirical observation of masonry specimens subjected to cyclic loading, allow to naturally keep track of the Damage Level (DL) reached by each deformable structural element-piers and spandrels-during the seismic input. The reaching of a DL in a structural element, i.e. the exceeding of the corresponding drift threshold, is related to the actual physical evolution of damage consisting of the widening and propagation of cracks ("hair-line cracks", "cracks", "large and extensive cracks", "serious failure" as mentioned in the damage description of Table 1). The drift thresholds may be differentiated for different failure modes—-such as those employed in the simulations and reported in Sect. 5.1 - and masonry typologies, based on data available in the literature from experimental campaigns (Kržan et al. 2015; Vanin et al. 2017; Morandi et al. 2018; Rezaie et al. 2020b; Boschi et al. 2021) or as recommended by national and international codes (for example, by the Italian NTC 2018, MIT 2019). Nonetheless, the proposed approach could be equally adopted for any constitutive law and extended to other modelling strategies (e.g. finite or discrete element models). In such a case, indeed, the association of the DL to each structural element can be implemented by the analyst in the ex-post processing of the data according to the same drift thresholds (or monitoring other ad-hoc damage variables, see Toti et al. 2015).

At the wall scale, a second issue regarding damage extension comes into play. The EMS-98 description, in this regard, is referring to the wall as an assemblage of masonry panels, potentially exhibiting different levels of damage. The same criteria, thus, should be pursued to interpret the simulated damage. A practical possibility is to define an average nondimensional damage level of the wall, named $\mathrm{DL}_{w}$, ranging between 0 and 5 taking into account the damage contribution of each structural element-piers and spandrels-as a function of its relative importance in the seismic response of the wall. In this respect, assuming a constant interstorey height with a regular distribution of windows, a quite accurate weight for piers can be related to the element horizontal cross-sectional resistant area (assuming their height to be the same), normalized to the total resistant area of the piers pertaining to the wall. Based on the above considerations, the average damage of the wall can be estimated as

$$
\mathrm{DL}_{w}=\frac{\sum_{p} A_{p} \mathrm{DL}_{p}}{\sum_{p} A_{p}}+c_{s, w} \frac{\sum_{s} \mathrm{DL}_{s}}{n_{s}}, \quad 0 \leq \mathrm{DL}_{w} \leq 5
$$

where the subscripts $p$ and $s$ in the damage levels $\mathrm{DL}_{p}$ and $\mathrm{DL}_{s}$ refer to pier and spandrel elements respectively, $A$ is the horizontal cross-sectional area, DL is the element damage level, $n_{S}$ is the total number of spandrel elements of the wall. The coefficient $c_{s, w}$ weights the relative importance held by spandrels in defining the damage level of the entire $w$ th wall. A first-instance option is to define this parameter as the ratio between the vertical surface occupied by spandrels and the total vertical surface of the wall. This evaluation can be further particularized based on an expert engineering judgement regarding the 
main seismic behaviour expected on the building - in which spandrels surely hold a role, based on their stiffness, strength and coupling with other retaining elements. For example, in presence of co-seismic retaining elements (such as tie rods, reinforced concrete edge beams), spandrels are expected not to be the dominant damage-prone element and this term can be neglected (i.e $c_{s, w}=0$ ). Finally, the discrete global damage grade of the building from wall scale $\widehat{\mathrm{DG}}_{w}$ can be quantitatively estimated interpreting the extension of damage on the walls— "very few", "many", "most”, "total (of)" walls—provided by quantitative adjectives of the EMS-98 scale (Table 1).

To estimate the percentage of walls that reached a certain damage level, the continuous variable $\mathrm{DL}_{w}$ is firstly discretized employing the binomial distribution (Lagomarsino and Giovinazzi 2006), associating the upper bounds of each membership to the probability of 0.5 in the corresponding cumulative distribution function. Such an assumption leads to the discretization

$$
\widehat{\mathrm{DL}}_{w}= \begin{cases}0, & 0 \leq \mathrm{DL}_{w} \leq 0.7 \\ 1, & 0.7<\mathrm{DL}_{w} \leq 1.6 \\ 2, & 1.6<\mathrm{DL}_{w} \leq 2.5 \\ 3, & 2.5<\mathrm{DL}_{w} \leq 3.4 \\ 4, & 3.4<\mathrm{DL}_{w} \leq 4.3 \\ 5, & 4.3<\mathrm{DL}_{w} \leq 5\end{cases}
$$

where the hat symbol indicates the integer variable. It is then possible to compute the cumulative percentage of walls that attained a certain damage level and establish the damage grade at the wall scale $\widehat{\mathrm{DG}}_{w}$, according to the thresholds proposed in Table 1. Indeed, the thresholds are understood as lower bounds, so that $\widehat{\mathrm{DG}}_{w}$ is determined as the highest attained damage grade. Weighting factors $c_{w}$ can be employed to take into account the importance of a particular wall in the global response of the building, for example, based on its reaction to a unitary pushover force field.

The above criterion, based on the evaluation of damage severity and diffusion on walls, is not suited to detect the activation of possible soft-storey mechanisms which, from an engineering point of view, could be reasonably associated with complete loss of seismic performance. To overcome this drawback, a useful rule acting on walls' damage at the interstorey level can be considered, monitoring the mean damage of piers at the $l$-th level $\mathrm{DL}_{w, l}$ as

$$
\mathrm{DL}_{w, l}=\frac{\sum_{p} A_{p, l} \mathrm{DL}_{p}}{\sum_{p} A_{p, l}}
$$

where the subscript $l$ limits the sum to the piers of wall $w$ belonging to the $l$-th level.

In the case of buildings with very large extensions, the controls at the wall scale may not be sufficient to identify conditions in which the horizontal load-bearing capacity of the building (referring to high-severity damage levels) is already compromised. For these reasons, it's beneficial to refer to heuristic criteria on a global scale. The combination with the global-scale damage control such as $\widehat{\mathrm{DG}}_{\vartheta}$, based on roof drift thresholds corresponding to conventional percentages of the total reacting base shear $V$ relative to the maximum $V_{y}$ on the pushover curve (Table 1, Fig. 3) ensures a more reliable DG evaluation. The global damage grade $\widehat{\mathrm{DG}}$ of the building is finally estimated as the maximum between the one at the wall scale $\widehat{\mathrm{DG}}_{w}$ and the one estimated at the global scale $\widehat{\mathrm{DG}}_{\vartheta}$ 


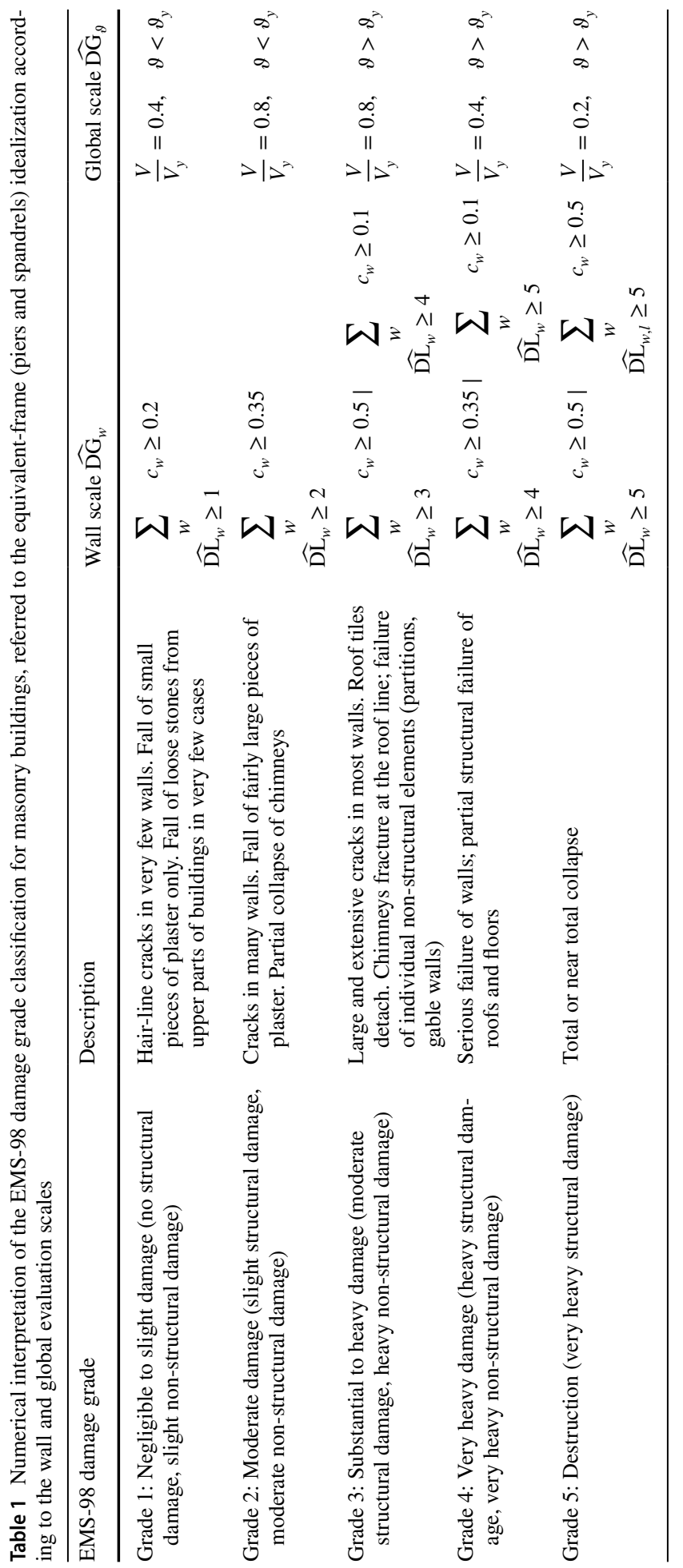



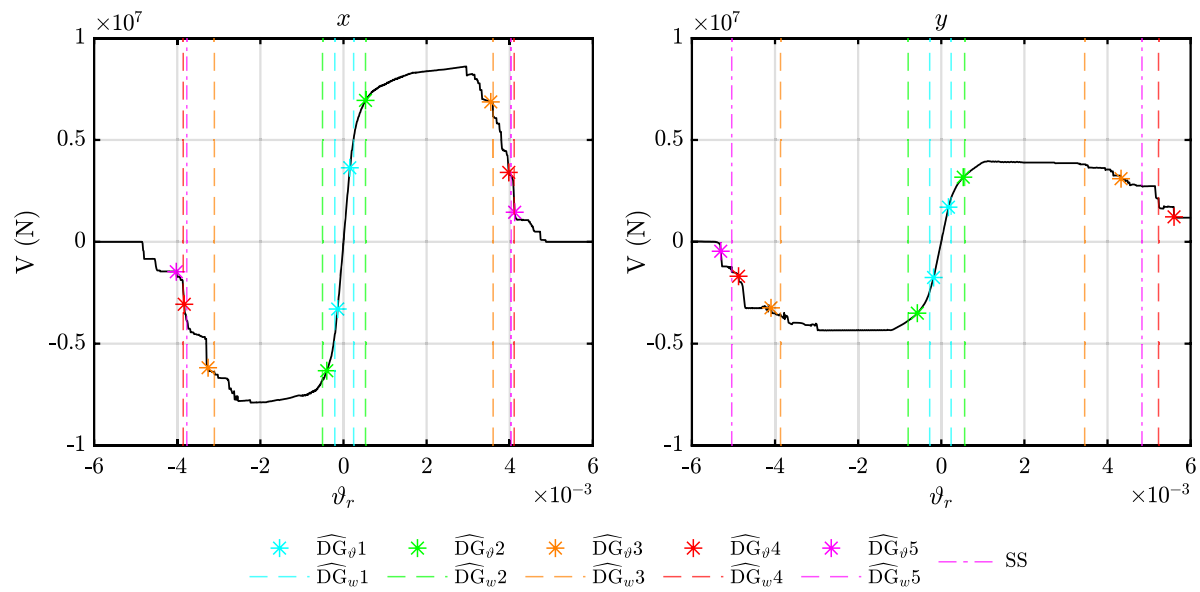

Fig. 3 Evaluation of the global damage grade from pushover analysis on the equivalent frame model of the Pizzoli town hall building (Sect. 5.1), according to the wall damage $\widehat{\mathrm{DG}}_{w}$ and global drift $\widehat{\mathrm{DG}}_{\vartheta}$ criteria (Table 1)

$$
\widehat{\mathrm{DG}}=\max \left\{\widehat{\mathrm{DG}}_{w}, \widehat{\mathrm{DG}}_{\vartheta}\right\}
$$

It should be remarked that, in principle, the described procedure-for what concerns the association of the global damage grade starting from the wall scale-should be equally applicable to interpret the actual damage that occurred on existing buildings, as long as accurate damage observations from field surveys are available. Such an application is not straightforward nor quick and, thus, cannot replace the synthetic approaches usually adopted in damage survey forms. Nevertheless, when detailed data is available, it can be very useful for the validation of numerical-based damage assessments, as it will be shown in the case of the Pizzoli town hall building (Sect. 5.1).

\section{Observed frequency variations in the Pizzoli town hall masonry building}

\subsection{Synthetic structural description of the benchmark case study}

The Italian Structural Seismic Monitoring Network (referred hereinafter as OSS, Dolce et al. 2017a), managed by the Italian Department of Civil Protection (DPC), monitors the dynamic response to earthquakes of around 150 buildings located in seismic risk-prone regions of Italy. In the framework of the DPC-ReLUIS Project 2017-2018, Research Line "Masonry Structures", Task 4.1-“Analysis of buildings monitored by the Italian Structural Seismic Monitoring Network (OSS)", monitoring data of buildings hit by the Central Italy earthquake sequence of 2016-2017 were jointly analysed by research groups belonging to different Italian universities (Cattari et al. 2019). The aim of the research was the employment of experimental dynamic measurements to support seismic assessment procedures for existing buildings.

Among the available case studies, the town hall building of Pizzoli constitutes an interesting benchmark example to investigate the natural frequency decrease phenomenon in 


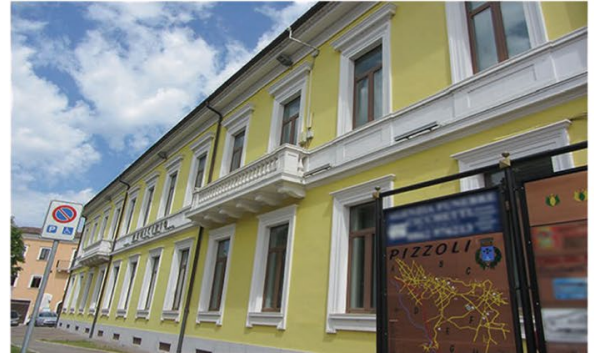

(a)

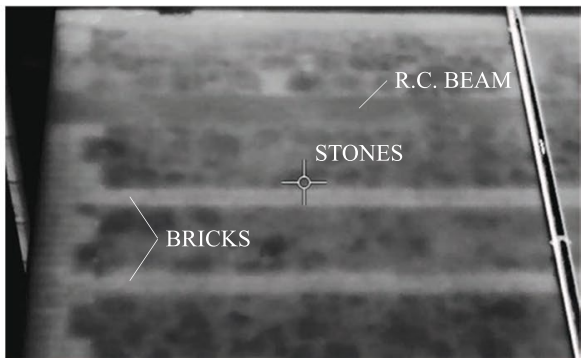

(b)

Fig. 4 The Pizzoli town hall building. a View of the façade, highlighting the elongated shape and the regular arrangements of openings on the perimeter walls. b Infrared thermography of a lateral perimeter wall, revealing the masonry typology made up of simple stones with brick courses. A reinforced concrete edge beam is visible at the floor diaphragm level

masonry buildings exhibiting light seismic damage. The structure was built in 1920 in the same-named city near L'Aquila, Abruzzo region, Italy. The building develops vertically with two floors above the ground. Externally, the structure shows a certain regularity in the arrangement of the openings, which are evenly distributed along the walls and vertically aligned (Fig. 4a). The building plan is characterised by an elongated rectangular shape$36.75 \mathrm{~m}$ in the $x$ direction, $11.9 \mathrm{~m}$ in the $y$ direction - with the longest side oriented in the EW direction. At the two extremities, two small projecting bodies give the plan a C-shape. Three main bearing walls run along the whole length of the building and are crossed, in the front part, by three orthogonal secondary walls. The interstorey height increases from $3.6 \mathrm{~m}$ at the ground level to $4.25 \mathrm{~m}$ at the first level, which is surmounted by a low-pitched concrete roof.

The in situ structural survey carried out in June 2017, together with the written documentation provided by DPC, provided valuable information about the building materials and the adopted structural solutions. The masonry piers are built with a cut local stone with courses of bricks - as clearly revealed by the thermographic imaging, Fig. 4b-varying in thickness from 65 to $75 \mathrm{~cm}$ at the first level, from 30 to $65 \mathrm{~cm}$ at the second level and from 45 to $65 \mathrm{~cm}$ in the attic. The masonry shows good interlocking, good quality of the mortar and firm transverse connection between wall facings. The floor diaphragms are composed of thin iron beams and hollow bricks capped by a concrete slab whose thickness reaches $16.5 \mathrm{~cm}$ and $12 \mathrm{~cm}$ at the first and the second level respectively.

Finally, for what concerns the mechanical properties of the subsoil, the existing documentation provides a time-averaged shear-wave velocity at $30 \mathrm{~m}$ depth of $666 \mathrm{~m} \mathrm{~s}^{-1}$, estimated through a seismic surface-wave method. As a preliminary classification, the soil falls within the class B defined by the European EN 1998-1 (CEN, 2004), which includes "deposits of very dense sand, gravel, or very stiff clay, at least several tens of metres in thickness, characterised by a gradual increase of mechanical properties with depth".

\subsection{Dynamic response to ambient excitations and varying environmental conditions}

The Pizzoli town hall building is equipped with a permanent dynamic monitoring system managed by OSS. The vibrational response is measured by one mono-axial and three 
bi-axial accelerometers, placed at the top of each level of the building, whereas the seismic input is measured by a triaxial accelerometer at its base. Further details regarding the sensor layout can be found in Spina et al. (2019). The monitoring is carried out through force-balance accelerometers with high sensitivity and wide dynamic range, suitable for both strong-motion earthquake and low-intensity vibrations (accelerations ranging from $1 \times 10^{-4} \mathrm{~g}$ to $2 \mathrm{~g}$ ). Signal digitization is managed by a 24 bit analog-to-digital converter, whereas synchronization is achieved by GPS receivers. In accordance with the aim of the OSS network - to record the dynamic response of structures to earthquakes - the monitoring is configured as a trigger-based system. Accelerations exceeding a pre-established threshold (typically $\pm 0.001 \mathrm{~g}$ ) automatically trigger the recording. Nevertheless, lowintensity vibrations can still be acquired manually. In this respect, a series of short ambient vibration acquisitions (coming from the commissioning test of the monitoring system) are employed to study the effects of variations in the environmental conditions on the dynamic behaviour of the structure. Such knowledge will be of primary importance in the evaluation of earthquake-induced frequency decrease (Sect. 4.4).

The 5 minutes-long measurements are acquired on a quite regular daily basis and cover a period of four months, from mid-February 2013 to the beginning of July 2013 (Fig. 5). The dynamic behaviour of the structure is identified from each available recording, by means of the classical output-only frequency domain decomposition technique (Brincker et al. 2001). In particular, the attention is focused on the frequency behaviour of the first and third structural modes, namely $\mathrm{T}_{x}$ and $\mathrm{T}_{y}$, each constituting the first mode of bending along each of the principal directions of the building - where the label T refers to the rigid translation of diaphragms in their plane (Sivori et al. 2021). These two modes are those expected to govern the seismic response of the structure along the two directions, thus of primary interest in the seismic analysis of the building (Sect. 5). High values of phase collinearity and Modal Assurance Criterion (Allemang 2003), both systematically greater than 0.9 , confirm the robustness of the identification and of the mode tracking, respectively.

For what concerns environmental conditions, the data shown in the following and analysed has been provided by the Italian "Centro Funzionale e Ufficio Idrografico Regione Abruzzo" in the form of temperature, humidity and rainfall raw measurements acquired by weather stations in Pizzoli and L'Aquila. Both the modes exhibit frequency shifts which appear to be moderately correlated with variations in ambient temperature, as reflected by the respective correlation coefficients (Table 2). The relative variations of the lowerfrequency mode $\mathrm{T}_{y}$ are satisfyingly explained by the least-squares linear regression model $\delta f=\beta \Delta T$ (bottom of Fig. 5), where $\delta f=\left(f-f_{r}\right) / f_{r}, \Delta T=T-T_{r}$ are estimated relative to the reference frequency and reference temperature $f_{r}, T_{r}$ as the mean values of the observation window-that is $f_{r}=\bar{f}, T_{r}=\bar{T}$. In accordance with the findings of other studies on masonry structures (mostly towers, see for example Saisi et al. 2015; Ubertini et al. 2017), the observed correlation is positive, so that an increase in temperature corresponds to an increase in natural frequency. No data are available to identify the behaviour below the freezing point of water, i.e. $0^{\circ} \mathrm{C}$. Conversely, the higher-frequency mode $\mathrm{T}_{x}$ exhibits a more scattered behaviour (as testified by the higher standard deviation of the error distribution in Table 2), which seems not to be completely explained considering the dependence on temperature alone.

To sum up, in the observed range of ambient temperature ranging from -0.30 to $26.1^{\circ} \mathrm{C}$, the first-order bending modes along each direction exhibit relative variations in the natural frequencies up to $\pm 5 \%$, of which around $\pm 3 \%$ are well explained by temperature variations. The effects of relative humidity and rainfall on the modal behaviour of the structure have been investigated as well. In general, a weaker correlation with frequency variations is 
Table 2 Sensibility of natural frequencies to variations in the ambient temperature

\begin{tabular}{llllllll}
\hline Mode & $\begin{array}{l}\text { Ref. frequency } \\
f_{r}=\bar{f}(\mathrm{~Hz})\end{array}$ & Type & Label & $\rho$ & $P$-value & $\beta_{\delta f, \Delta T}^{\dagger}$ & RMSE \\
\hline 1 & 4.61 & $\begin{array}{c}\text { First-order ver- } \\
\text { tical bending } \\
\text { along } y\end{array}$ & $\mathrm{~T}_{y}$ & 0.60 & $1.00 \times 10^{-10}$ & 0.0018 & 0.0106 \\
3 & 6.57 & $\begin{array}{l}\text { First-order ver- } \\
\text { tical bending } \\
\text { along } x\end{array}$ & $\mathrm{~T}_{x}$ & 0.48 & $9.67 \times 10^{-7}$ & 0.0023 & 0.0188 \\
& & & & & & \\
\hline
\end{tabular}

Correlation coefficient $\rho, P$-value, coefficient of linear regression $\beta$, Root Mean Squared Error (RMSE)

${ }^{\dagger}$ Ref. temperature $T_{r}=\bar{T}=9.46^{\circ} \mathrm{C}$

found, particularly for what concerns the daily rainfall level (effect which could be related to the quite good mechanical properties of the subsoil, see Sect. 4.1). In the light of these results, only the effects of temperature variations on natural frequencies are accounted for in the following of the article. The variation of damping ratio has not been investigated, this parameter is thus intended as unaffected by the atmospheric conditions.
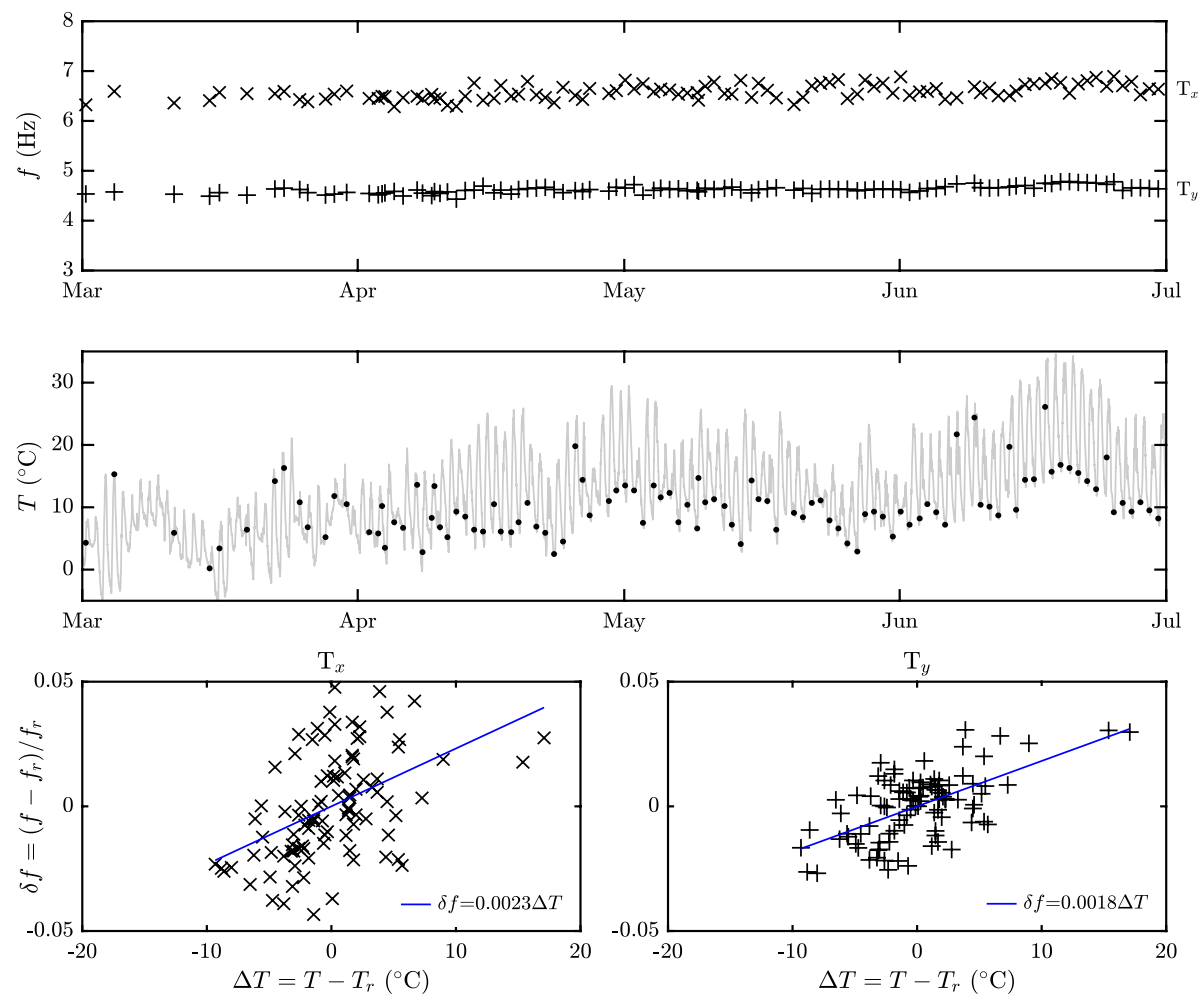

Fig. 5 Variation in the frequency of the first-order bending mode along each principal direction of the building $\left(\mathrm{T}_{x}, \mathrm{~T}_{y}\right)$, identified from daily ambient vibration recordings. Relative variations up to $\pm 3 \%$ with respect to the mean are attributable to fluctuations in the environmental temperature $T$ 
Table 3 Characteristics of the main events of the 2016-2017 Central Italy earthquake sequence, recorded by the dynamic monitoring system of the Pizzoli town hall building

\begin{tabular}{llllll}
\hline Site time (UTC) & Epicentre & $M_{W}$ & $\begin{array}{l}\text { Site distance } \\
(\mathrm{km})\end{array}$ & PGA $_{x}(g)$ & PGA $_{y}(g)$ \\
\hline 24-08-2016 01:36:38 & Accumoli (RI) & 6.0 & 29.6 & 0.079 & 0.087 \\
26-10-2016 17:10:10 & $\begin{array}{c}\text { Castelsantangelo sul } \\
\text { Nera (MC) }\end{array}$ & 5.4 & 50.9 & 0.022 & 0.022 \\
& $\begin{array}{l}\text { Visso (MC) } \\
\text { 26-10-2016 19:17:35 }\end{array}$ & 5.9 & 54.9 & 0.021 & 0.024 \\
30-10-2016 06:40:26 & Norcia (PG) & 6.5 & 46.6 & 0.101 & 0.101 \\
18-01-2017 10:14:12 & Capitignano (AQ) & 5.5 & 10.6 & 0.089 & 0.082 \\
\hline
\end{tabular}

The epicentre and moment magnitude $M_{W}$ are provided by the National Institute of Geophysics and Volcanology (INGV, http://terremoti.ingv.it). Maximum Peak Ground Acceleration (PGA) recorded at the base along each of the two principal directions of the structure

\subsection{Damage state during the Central Italy earthquake sequence of 2016-2017}

The Pizzoli town hall monitoring system was already operative in 2009 , when a strong earthquake hit L'Aquila region. The building remained substantially undamaged after the mainshock and several aftershocks (Spina et al. 2011). Conversely, after the Central Italy earthquake sequence of 2016-2017 (see Sect. 4.4, Table 3 for more details regarding each earthquake magnitude), the building was declared unusable for safety reasons.

The structure exhibited a global response associated with the in-plane response of masonry walls. The damage state remained mild up to the seismic events of 30 October 2016 and 18 January 2017 (which caused the highest interstorey and roof drift respectively, see Table 4), during which it grew to moderate. Damaging has been mainly observed in the piers along the shorter sides, characterized (i) at the ground level, by the presence of pseudo-horizontal cracks associated with a flexural response of piers and shear-failure diagonal cracks (Fig. 6a) and (ii) at the first level, by horizontal cracks at the top of extremities-piers and pseudo-vertical cracks in central piers (Fig. 6b). Some detachments and a general slight cracking pattern have been observed on the floor diaphragms as well, particularly at the top of the first floor.

A detailed survey of the damage observed inside and outside of the structure was carried out in June 2017, within the context of ReLUIS project activities (Cattari et al. 2019).

Table 4 Relationship between the maximum response and the post-seismic decrease of natural frequencies for the Pizzoli town hall building during the 2016-2017 Central Italy earthquake sequence

\begin{tabular}{lllllll}
\hline Site time (UTC) & $\theta_{i, x}$ & $\delta f_{\mathrm{T}_{x}}$ & $\mathrm{MAC}_{\mathrm{x}}$ & $\theta_{i, y}$ & $\delta f_{\mathrm{T}_{y}}$ & MAC $_{\mathrm{y}}$ \\
\hline 24-08-2016 01:36:38 & 0.0046 & -0.130 & 0.99 & 0.0042 & -0.183 & 0.97 \\
26-10-2016 17:10:10 & 0.0004 & -0.129 & 0.96 & 0.0004 & -0.100 & 0.99 \\
26-10-2016 19:17:35 & 0.0014 & -0.055 & 0.99 & 0.0012 & -0.058 & 0.98 \\
30-10-2016 06:40:26 & 0.0108 & -0.163 & 0.98 & 0.0083 & -0.201 & 0.99 \\
18-01-2017 10:14:12 & 0.0016 & -0.138 & 0.99 & 0.0018 & -0.155 & 0.99 \\
\hline
\end{tabular}

Maximum interstorey drift $\theta_{i}$, estimated by frequency-domain double-integration of the acceleration response to the earthquake. Natural frequency variation $\delta f$ and MAC value for the first bending mode along each main direction, identified by comparing the leading and trailing vibrational response of the structure 


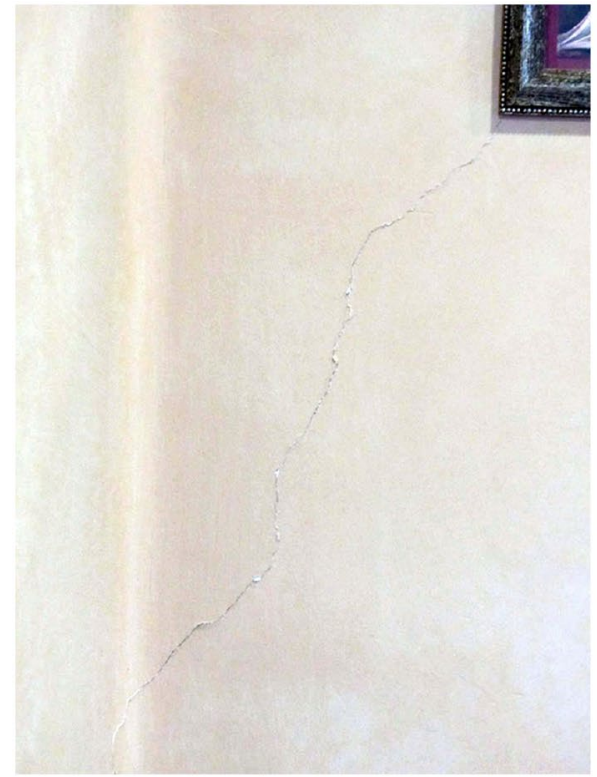

(a)

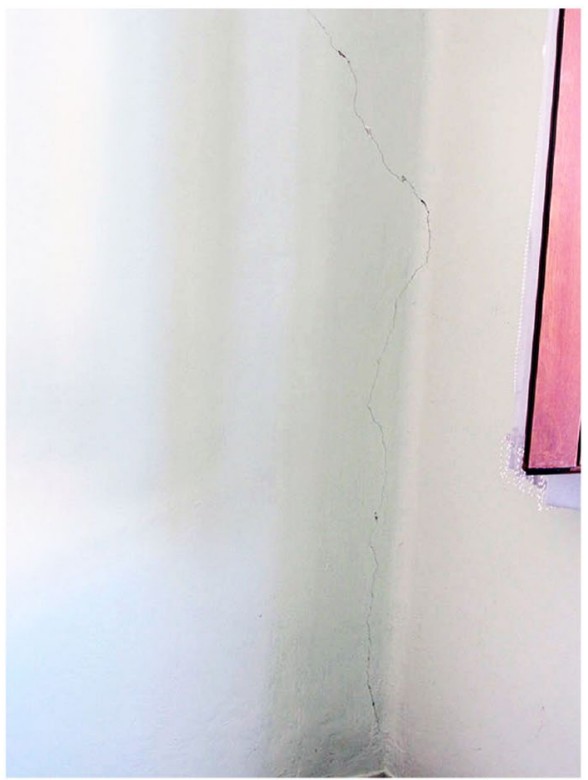

(b)

Fig. 6 Damage to masonry piers in the Pizzoli town hall building, surveyed in June 2017. a Diagonal and b pseudo-vertical cracks have been observed respectively at the ground level and first level of the building, at the corner between walls 1 and 9 (see Fig. 11a)

The interested reader may refer to Degli Abbati et al. (2021) for a detailed representation of the cracking pattern and Cattari and Angiolilli (2022) for an accurate interpretation of the occurred damage, starting from the masonry panels up to the attribution of a global damage level consistent with the EMS-98 scale (Grünthal 1998). Definitely, the latter can be defined as slight-to-moderate, corresponding to a Damage Grade 2 (DG2) according to the EMS-98. The dynamic response of the structure during the earthquake sequence as recorded by the seismic monitoring system, suggesting the occurrence of moderate structural damage according to previous studies (Ceravolo et al. 2018; Spina et al. 2019; Miraglia et al. 2020), will be analysed in terms of post-seismic frequency reductions in Sect. 4.4.

\subsection{Observation of earthquake-induced natural frequency reduction from seismic monitoring data}

Besides long (order of tens of minutes) time-histories of ambient vibrations, acquired after seismic events of relevant intensity for identification purposes and condition assessment, the OSS monitoring system automatically acquires short (order of tens of seconds) recordings of the dynamic response to the earthquakes exciting the structure. The leading idea of this Section is (i) to exploit the pre and post-event parts of the structural response of the Pizzoli town hall building to identify, respectively, the pre and post-earthquake values of the natural frequencies of the structure, (ii) to relate eventual frequency variations to other Engineering Demand Parameters (EDPs) representative of the response and useful for damage assessment purposes - such as the maximum interstorey drift reached during the 
event. This approach, however, comes with strong limitations related to the trigger-based acquisitions-not specifically conceived for the accurate monitoring of the post-seismic evolution of dynamic properties of the structure. The first drawback is the shortness of the available pre and post-event ambient noise, which limits the frequency resolution achievable from the identification and enhances the detrimental effect of unwanted seismic components. The second limit deals with slow frequency-recovery phenomena which, as previously discussed (Sect. 2), can last for days or weeks. This effect can be accounted for by comparing two consecutive pre-event identifications sufficiently spaced in time, assuming no other unmeasured seismic events have affected the damage state of the structure-and carefully accounting for the dynamic effects of environmental variations, such as those in ambient temperature.

The natural frequency variations following the seismic event are extracted (i) pre-processing the seismic input at the base of the building, defining the pre and post-event times through appropriate threshold-based and energy-based criteria, (ii) identifying the pre and post-event values of natural frequencies from the corresponding response of the building, i.e. the leading and trailing quasi-ambient noise. All the signals are low-pass filtered and decimated from the original sampling frequency of $250 \mathrm{~Hz}$ to $25 \mathrm{~Hz}$. Task (i) is carried out employing a classical moving-average approach, in which the start of the event $t_{s}$ corresponds to the ratio between a short time-averaging (STA) window of length $0.4 \mathrm{~s}$ over a long time averaging (LTA) window of length $60 \mathrm{~s}$ exceeding the trigger value of 2 (top of Fig. 7). The live-time of the seismic event $t_{s}$ to $t_{e}$ is defined as the part of the signal accounting for $99.5 \%$ of the total energy carried by the earthquake. This allows extracting the leading-environmental noise-to-seismic excitation-and the trailing — seismic excitation-to-environmental noise-part of the response for identification purposes and, at the same time, avoiding most of the unwanted seismic disturbance. Accordingly, the dynamic identification is carried out via an output-only approach, employing the frequency domain decomposition technique (Brincker et al. 2001). Given the limited length of the ambient vibration response, which determines a poor frequency resolution, no further investigation is pursued about damping variations. Natural frequencies are identified- $f_{s}$ from the leading and $f_{e}$ from the trailing response-as the median value of the spectral amplification bell of the first singular value (bottom of Fig. 7), being the modes well-separated in the investigated frequency band. The bell, in particular, is identified applying a coupled phase collinearity-MAC spatial filtering. MAC values greater than 0.8 ensure the comparison between the pre and post-event identifications is carried out pairing the same natural mode.

Among the wide database of available seismic recordings, the investigation is focused on the main seismic events of the 2016-2017 Central Italy earthquake sequence. In particular, the most energetic earthquakes (moment magnitude $M w \geq 5$ ) belonging to the sequence are those considered in the following analysis (Table 3). All the events selected were recorded by the monitoring system and, due to their distance from the town of Pizzoli, hit the structure with different strengths. The relative frequency variations $\delta_{f}=\left(f_{s}-f_{e}\right) / f_{e}$ are identified for the first-order bending modes along each principal direction of the building $\mathrm{T}_{x}, \mathrm{~T}_{y}$, then related to the corresponding maximum interstorey drifts $\theta_{i}=\max \left(|\Delta u| / h_{i}\right)$ along the same direction-where $\Delta u$ is the difference in the horizontal displacements measured at the top and bottom of the storey, $h_{i}$ is the interstorey height. This parameter is chosen as a representative measure of the global seismic response of the building. In particular, the displacements at the storey level are estimated by frequency-domain double-integration of the acceleration response in the range $0.1-25 \mathrm{~Hz}$ (Table 4). The maximum relative frequency reduction appears to follow the seismic event of 30 October 2016 with epicentre in Norcia (PG). The natural frequencies of the first-order bending modes 

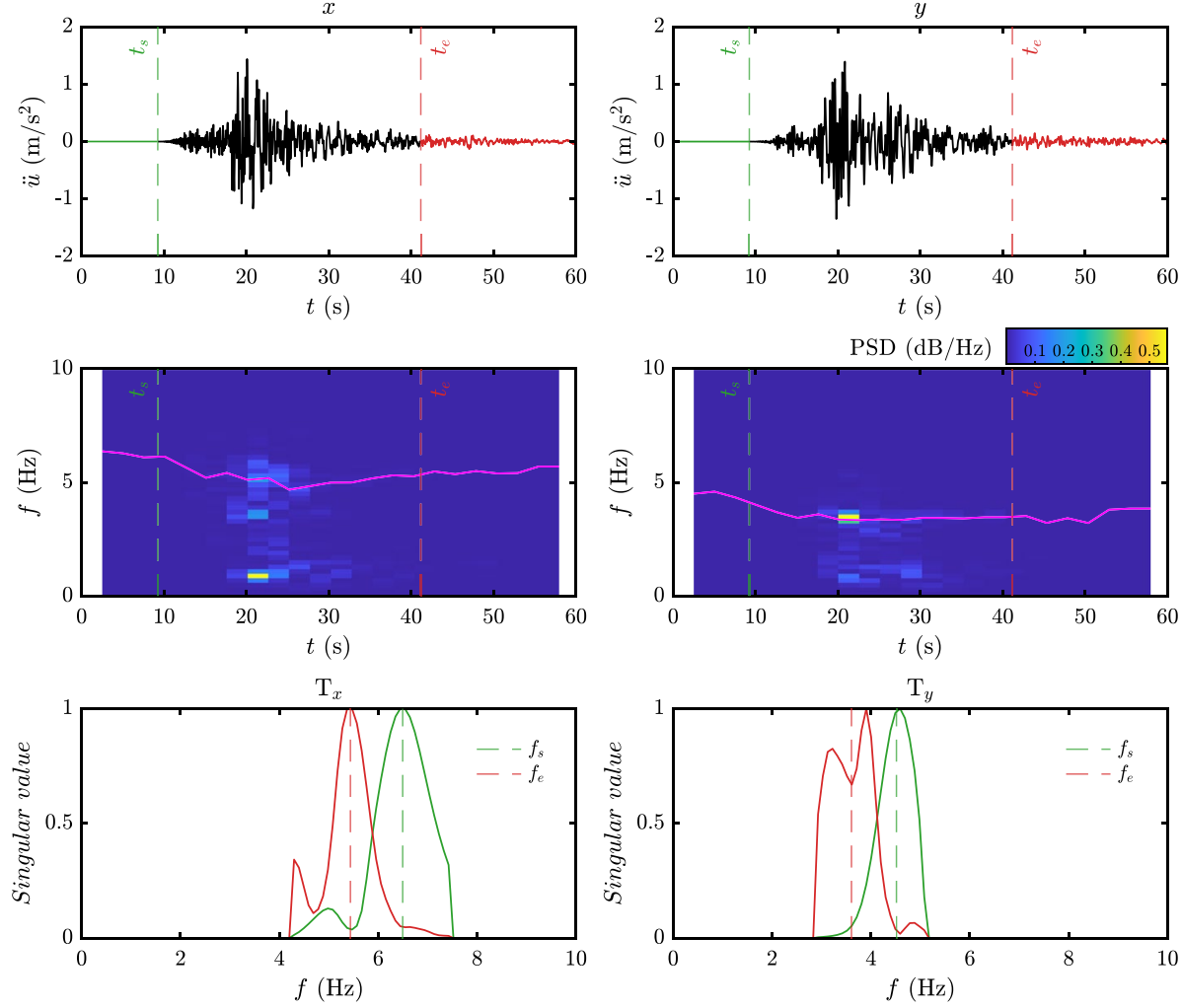

Fig. 7 Identification of the pre and post-event (top) values of natural frequencies $f_{s}$ and $f_{e}$ for the first-order bending mode along each main direction of the building, by means of frequency domain decomposition (bottom). The time-frequency analysis (mid) shows an amplitude-dependent behaviour, in which the amplification frequencies reach the minimum value for the maximum response amplitude

along the $x$ and $y$ directions $\mathrm{T}_{x}$ and $\mathrm{T}_{y}$ undergo a relative decrease roughly equal to $16 \%$ and greater than $20 \%$, respectively. It should be noted that, among those considered in the analysis, the Norcia earthquake is the seismic event characterized by the highest Peak Ground Acceleration (PGA, Table 3) at the site and causing the highest interstorey drift in the structure (Table 4). More generally, the reduction of natural frequencies seems to agree with the actual observation of damage accumulation, which grew from the mild state of August to a moderate state after the seismic events of October (Sect. 4.3).

The analysis highlights (i) an amplitude-dependent behaviour (Sect. 2), in which the vibration frequency reaches a minimum value in correspondence of the maximum response amplitude (as shown by the frequency ridge of the Fourier spectrogram with $5 \mathrm{~s}$ time-window and 50\% overlap, mid of Fig. 7) and (ii) a nonlinear relationship between the maximum interstorey drift and the frequency decrease along the $y$ direction (cross marks, right side of Fig. 8). Regarding point (i) it seems clear that, even with all the necessary precautions adopted, the pre and post-event responses still suffer from residual effects of the seismic excitation, so that the output-only identification results are affected by nonstationary levels of vibration amplitude-with RMS values one order of magnitude larger than those typical of the pre-event environmental noise. This issue could be easily avoided by 


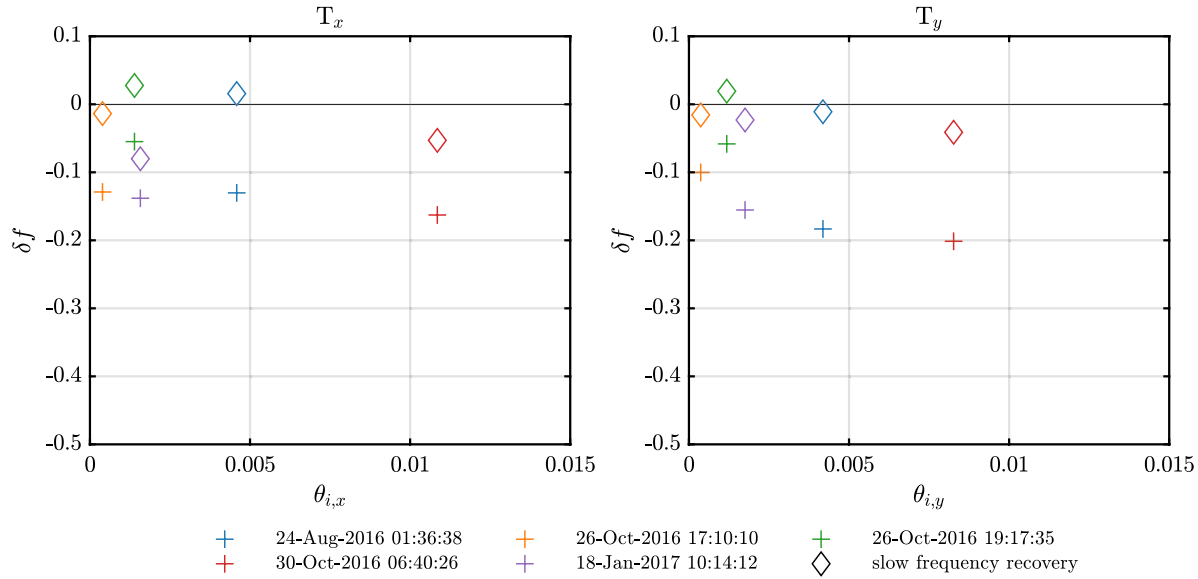

Fig. 8 Relative reduction $\delta_{f}$ of natural frequencies of the Pizzoli town hall building following the main seismic events of the 2016-2017 Central Italy earthquake sequence, as a function of the maximum interstorey drift $\theta_{i}$ measured along the main directions $x, y$ of the building. The frequency reduction is estimated, for each first-order bending mode $\mathrm{T}_{x}, \mathrm{~T}_{y}$, comparing the leading and trailing vibrational response to the earthquake. Diamond marks show the role of slow frequency recovery phenomena

measuring the structural response for longer times, i.e. increasing the pre and post-event recording times and introducing suited choices to store and treat a larger amount of data. This statement should not be interpreted as criticism towards current trigger-based monitoring systems, rather as a proposal in the evolving seismic-structural monitoring paradigm. For what concerns point (ii), as already mentioned, the evaluation is not accounting for the slow frequency recovery phenomenon occurring over time intervals of days. Rather than employing the leading and trailing responses of the same event, the decrease of frequency is evaluated considering two subsequent events sufficiently spaced in time, accounting for different temperature conditions through the regression model previously developed (Sect. 4.2). The analysis shows that the pre-damage values of natural frequencies are partially recovered over time (diamond marks in Fig. 8). The frequency slow-recovery is comparable with the earthquake-induced reduction, revealing this effect as a critical issue for a reliable frequency-based estimation of damage in masonry buildings, particularly in the immediate post-emergency phase.

\section{Experimental application: the frequency reduction-damage seismic chart of the Pizzoli town hall building}

\subsection{Simulation strategy}

The model-based methodology for the development of frequency reduction-damage seismic charts of monitored masonry buildings, theoretically presented in Sect. 3, is exemplified in the case of the Pizzoli town hall. The application employs the equivalent frame model of the building - developed and dynamically calibrated (Sivori et al. 2021) as well as validated (Degli Abbati et al. 2021) in previous works - to execute several nonlinear dynamic analyses, exploring increasing states of structural damage. 
In this regard, among various possibilities, the investigation of the frequency-damage relationship is pursued via Multiple Stripe Analysis (MSA, Jalayer and Cornell 2009). The analysis of MSA results allows estimating the distribution of the EDPs for increasing seismic actions experienced by the structure, addressing the potential record-to-record variability. The numerical simulations employ the natural accelerograms selected in the RINTC Project (the acronym for "Implicit Seismic Risk of Code-Conforming Structures", Iervolino and Dolce 2018; RINTC Workgroup 2018), in which five Italian sites, ten return periods of the seismic event and two soil conditions were considered to span a wide range of seismic hazard levels within the country. This set of seismic inputs has been already employed in the framework of other research studies addressing the solution of nonlinear dynamic analyses on equivalent frame models, also confirming the reliability and computational efficiency of this modelling approach (Cattari et al. 2018). In particular, the simulations employ the ground motion selection referred to the site of L'Aquila, site very close to Pizzoli, and the rock soil condition (Iervolino et al. 2018). The signals may be considered realistic for this first exemplification of the proposed procedure, although it is evident that the elaboration of frequency reduction-damage seismic charts for a specific strategic building could benefit from a more refined selection of seismic ground motions, specific to the soil site and amplitudes of interest and accounting for disaggregation studies. Nowadays, such a targeted selection may be feasibly supported by software available in the literature (such as Iervolino et al. 2010).

More specifically, return periods of the seismic action ranging from 10 to 1,00,000 years (Table 5) have been considered. In particular, each return period corresponds to a set of 20 bi-directional natural accelerograms properly scaled to be compatible on average, at a fixed structural period $\mathrm{P}_{1}$, with the spectral acceleration $\mathrm{S}_{\mathrm{a}}\left(\mathrm{P}_{1}\right)$ resulting from the probabilistic seismic hazard study at the site. For the purposes of this study, the reference period $P_{1}$ is selected to be $0.15 \mathrm{~s}$, consistently with the fundamental natural periods of the Pizzoli town hall buildings (around $0.217 \mathrm{~s}$ and $0.152 \mathrm{~s}$ for the first-order bending modes along each principal direction, see Sect. 4.2).

To optimize the computational efficiency of the simulation, the natural earthquake signals are pre-processed through low-pass filtering and decimation, down to a sampling

Table 5 Return period and average spectral acceleration $\mathrm{S}_{\mathrm{a}}\left(\mathrm{P}_{1}\right)$ at $\mathrm{P}_{1}=0.15 \mathrm{~s}$ of each IM-stripe considered in the Multiple Stripe Analysis (MSA) framework (bedrock soil condition)

\begin{tabular}{lclllll}
\hline Stripe & Return period (years) & $\mathrm{S}_{\mathrm{a}}\left(\mathrm{P}_{1}\right)(\mathrm{g})$ & $\overline{\mathrm{DG}}_{x}$ & $\overline{\delta f}_{\mathrm{T}_{x}}$ & $\overline{\mathrm{DG}}_{y}$ & $\overline{\delta f}_{\mathrm{T}_{y}}$ \\
\hline $\mathrm{IM} 1$ & 10 & 0.011 & 0 & -0.031 & 0.70 & -0.046 \\
$\mathrm{IM} 2$ & 50 & 0.220 & 0.65 & -0.065 & 1.15 & -0.101 \\
$\mathrm{IM} 3$ & 100 & 0.352 & 1.20 & -0.144 & 1.65 & -0.215 \\
$\mathrm{IM} 4$ & 250 & 0.493 & 1.80 & -0.203 & 1.90 & -0.292 \\
$\mathrm{IM} 5$ & 500 & 0.658 & 2.20 & -0.358 & 2.85 & -0.458 \\
$\mathrm{IM} 6$ & 1000 & 0.858 & 2.45 & -0.400 & 3.25 & -0.552 \\
$\mathrm{IM} 7$ & 2500 & 1.132 & 3.25 & -0.589 & 3.65 & -0.662 \\
$\mathrm{IM} 8$ & 5000 & 1.471 & 3.95 & -0.712 & 4.20 & -0.730 \\
$\mathrm{IM} 9$ & 10,000 & 2.056 & 4.70 & -0.791 & 4.65 & -0.767 \\
$\mathrm{IM} 10$ & $1,00,000$ & 3.417 & 4.75 & -0.807 & 4.85 & -0.778 \\
\hline
\end{tabular}

Average frequency relative reduction $\overline{\delta f}$ and global damage grade $\overline{\mathrm{DG}}$ caused on the Pizzoli town hall by each stripe, as resulting from numerical simulations 
frequency of $50 \mathrm{~Hz}$. In particular, the analyses are performed with the research implementation of the TREMURI software (Lagomarsino et al. 2013), describing masonry panels as nonlinear beams through a piecewise linear constitutive law developed in Cattari and Lagomarsino (2013) and recently validated in Brunelli et al. (2021). The formulation allows to account for (i) the stiffness degradation in the nonlinear regime (in a simplified way, by assigning the ratio between the secant and initial stiffness), (ii) the attainment of maximum shear strength according to common strength criteria proposed in the literature (Calderini et al. 2009) and (iii) the hysteretic behaviour differentiated for the flexural, shear and hybrid failure modes, according to a phenomenological approach. The interested reader may refer to Cattari and Lagomarsino (2013); Cattari et al. (2018); Angiolilli et al. (2021) for further details. For the case of Pizzoli's town hall, the input parameters necessary to completely describe the response of panels in the linear and nonlinear regime are reported in Sivori et al. (2021); Degli Abbati et al. (2021), as resulting from the aforementioned calibration and validation activities on the numerical model. Table 6 synthetically provides an overview of, first, the relationship between element drift, residual strength and corresponding DL, second, the calibrated mechanical moduli and, third, the strength parameters of the masonry. These latter are defined coherently with the masonry typology observed on the building, according to the reference values proposed in the Italian building code NTC 2018 (MIT, 2019)—namely those referring to the cut stone masonry with good bond pattern and presence of brick courses (Sect. 4.1). An exemplification of the constitutive law for pier elements is reported in Fig. 9 a for the shear damage modality, in Fig. 9b for the flexural one. It should be finally noted that, according to the assumed law, the stiffness secant to the maximum shear strength (attainment of DL2) is equal to $60 \%$ of the initial elastic stiffness. This degradation plays a role in determining the ambient response of the structure following slight damage, i.e. in the low drift range. At the global scale, however, the effect on the vibration frequency can be regarded as secondary to the one caused by damage distribution among the elements.

While Degli Abbati et al. (2021) discusses the capability of the model in reproducing the floor spectra in various points of the structure, as well as giving an overall view of the simulated damage to the 2016-2017 Central Italy earthquake sequence, Fig. 10 shows a

Table 6 Strength-drift-damage relationship and mechanical parameters assumed for the cut stone masonry of the Pizzoli town hall building

\begin{tabular}{llllll}
\hline$p / s$ & \multicolumn{2}{l}{ Shear behaviour } & & \multicolumn{2}{l}{ Flexural behaviour } \\
\cline { 2 - 3 } \cline { 5 - 6 } & $\theta_{e}(\%)$ & $\beta_{e}$ & & $\theta_{e}(\%)$ & $\beta_{e}$ \\
\hline DL3 & $0.45 /^{\dagger}$ & $0.6 / 0.7$ & & $0.6 / 0.6$ & 1.0 \\
DL4 & $0.7 / 0.4$ & $0.1 / 0.7$ & & $0.8 / 0.8$ & $0.8 / 0.7$ \\
DL5 & $0.9 / 0.7$ & 0 & $1.1 / 1.2$ & 0 \\
\hline$E_{m}(\mathrm{~Pa})$ & $G_{m}(\mathrm{~Pa})$ & $f_{c}(\mathrm{~Pa})$ & $\tau_{0}(\mathrm{~Pa})$ & $\rho_{m}\left(\mathrm{~kg} \mathrm{~m}^{-3}\right)$ \\
\hline $2.7 \times 10^{9}$ & $0.9 \times 10^{9}$ & $5.95 \times 10^{6}$ & & $0.12 \times 10^{6}$ & 2100 \\
\hline
\end{tabular}

Thresholds for the element drift $\theta_{e}$ and relative residual strength $\beta_{e}$ adopted for piers $p$ and spandrels $s$ and corresponding to the attainment of a damage level DL, for shear and flexural behaviours. Young $E_{m}$ and shear $G_{m}$ stiffness moduli, compressive $f_{c}$ and shear $\tau_{0}$ strengths, mass density $\rho_{m}$

$\theta_{e, \mathrm{DL} 2}$ corresponds to the reaching of the peak strength, $\theta_{e, \mathrm{DL} 1}$ to the $70 \%$ of the peak strength on the initial elastic branch. ${ }^{\dagger}$ For spandrels, $\theta_{e, D L 3}$ has been defined assuming a ductility factor equal to 4 (Beyer and Mangalathu 2013) 


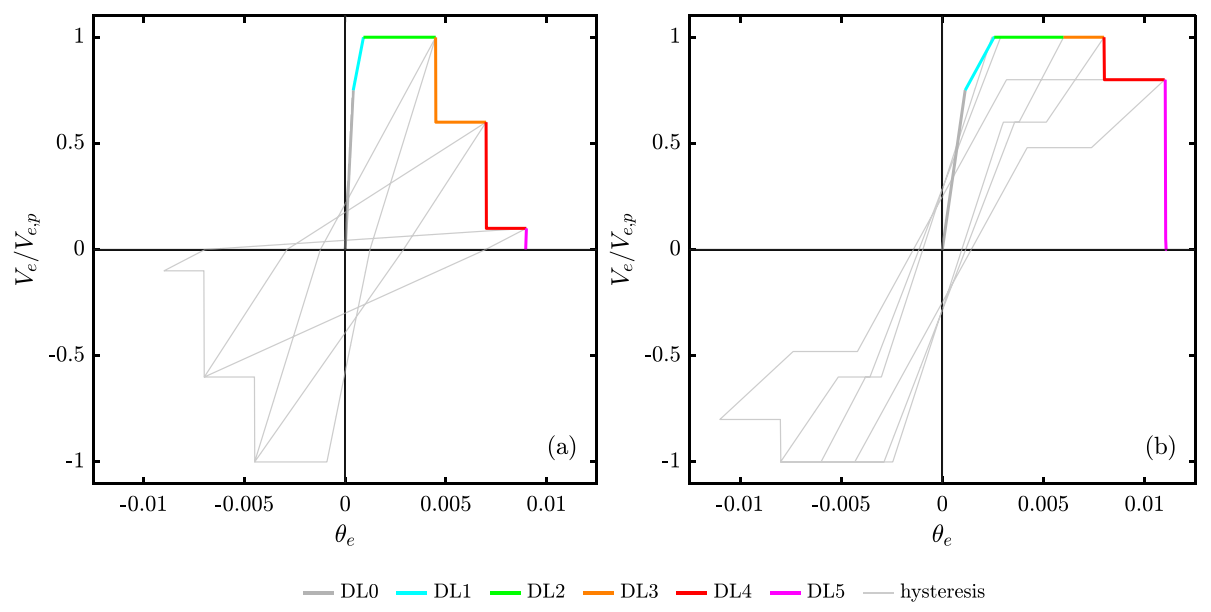

Fig. 9 Piecewise linear constitutive law assumed for pier elements, in terms of shear $V_{e}$ over the maximum resistant shear $V_{e, p}$ as function of the element $\operatorname{drift} \theta_{e}$. The figure shows the progressive strength reduction corresponding to the attainment of increasing DLs, accompanied by a stiffness degradation in the hysteretic behaviour for $\mathbf{a}$ shear and $\mathbf{b}$ flexural failure modes
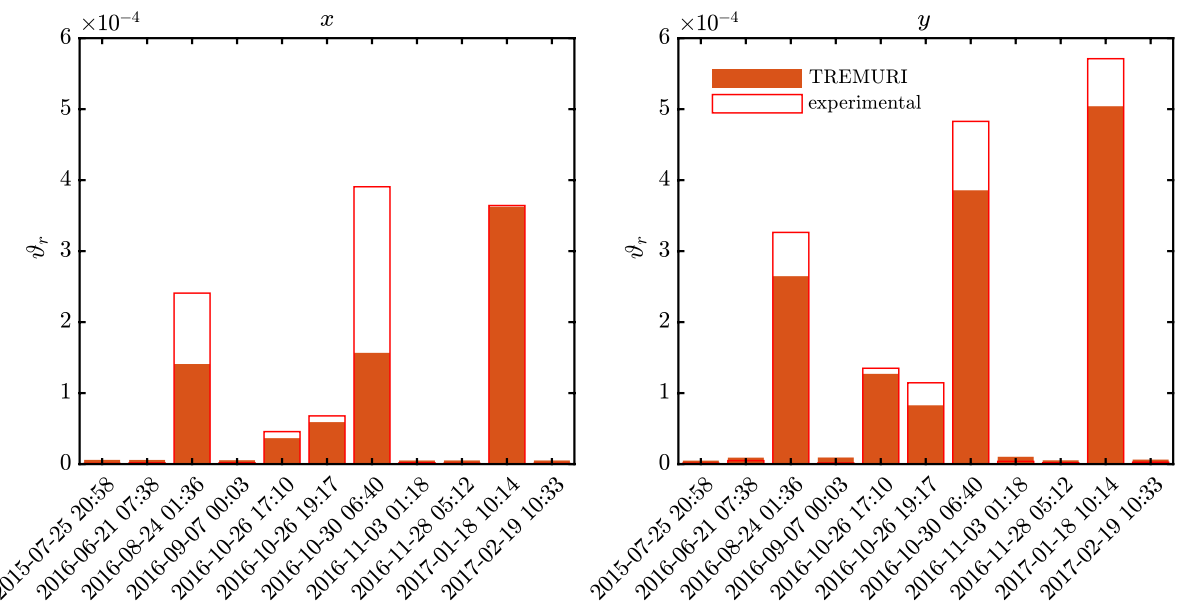

Fig. 10 Comparison between the TREMURI predictions and the experimental response of the Pizzoli town hall building during minor and major seismic events in 2016-2017, reported in terms of maximum roof drift. The average roof displacement is estimated from frequency-domain integration of the measured acceleration response in the range $0.1-25 \mathrm{~Hz}$

more detailed comparison in terms of predicted maximum roof drifts $\theta_{r}$ with respect to those recovered by OSS acceleration measurements (Sect. 4.4). The simulations, despite neglecting the effects of damage accumulation, highlights the capability of the model to reproduce the global response of the structure in a satisfying manner, with a slight underestimation of floor relative displacements. In particular, referring to the main earthquakes that hit the structure until the 18th of January 2017, the application of the damage assessment procedure proposed in Sect. 3.3 to (i) the damage surveyed on the structure in June 

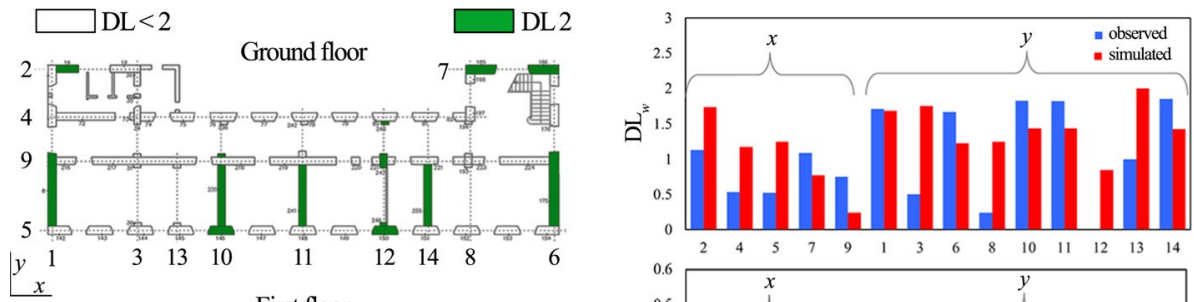

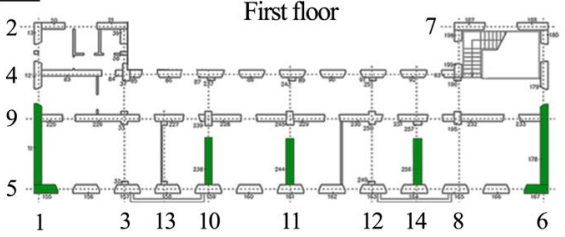

(a)

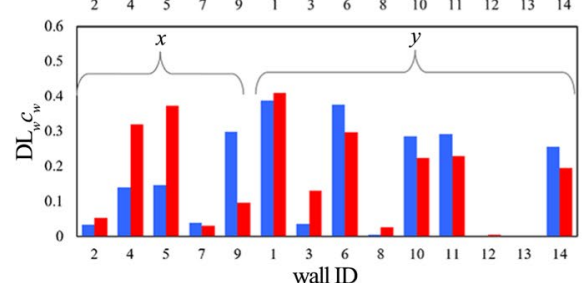

(b)

Fig. 11 Observed and simulated damage in the Pizzoli town hall building, caused by the main seismic events hitting the structure up to the 18th January 2017. a Observed damage level of piers element, b comparison between the average damage level at the wall scale estimated from direct observations and from simulations

2017 (Fig. 11a) and (ii) to the results of nonlinear dynamic analysis on the EFM shows a good agreement in terms of damage severity and distribution among the different walls (Fig. 11b).

The solution of the time-history analysis is obtained through a Newmark integration method, assuming a Rayleigh viscous damping $\zeta$ equal to 0.03 for the first $\mathrm{T}_{y}$ and fourth $\mathrm{T}_{x}$ modes. In succession, thanks to the research version of the solver allowing to keep in memory the damage state achieved after each analysis, the structure is subjected to a base input of $50 \mathrm{~s}$ zero-mean Gaussian white noise of low intensity, uncorrelated along the two components, sampled at $200 \mathrm{~Hz}$. This allows simulating the post-earthquake ambient behaviour of the damaged building, identifying its decreased natural frequencies through a pseudo-experimental modal identification. The increased sampling time, as specified in Sect. 3.1, avoids potential frequency aliasing phenomena-possibly leading to the increase of the simulated oscillations periods.

\subsection{Developing the model-driven frequency reduction-damage seismic chart of the building}

To track the decrease of the fundamental frequencies of the building due to earthquakeinduced structural damage, the EF model of the building has been excited with a base zero-mean Gaussian white noise of low intensity, postponed to the seismic input. This strategy allows simulating the post-seismic pseudo-experimental ambient response of the structure, ruling out any possible influence of undesired frequency content of the seismic input. Similarly to the experimental application (Sect. 4.4), the identification algorithm involves the use of the output-only Frequency Domain Decomposition technique (Brincker et al. 2001), to keep track of the frequency reduction of the first two translational modes of the building $-\mathrm{T}_{x}$ calibrated at $4.44 \mathrm{~Hz}$ and $\mathrm{T}_{y}$ at $7.06 \mathrm{~Hz}$, Sivori et al. (2021) — at the end of the seismic event, checking the invariance of their mode shapes. This last and only requirement, on the one hand, allows the identified frequency reductions to be associated with a particular mode and, on the other hand, ensures that 
only damage states that do not significantly alter the dynamic behaviour of the building are taken into account. In particular, such control is implemented verifying the correlation between the mode shapes of the numerical model in the undamaged and damaged state, i.e. the MAC value, to be equal or greater than 0.8 . To be consistent with the experimental results, the evaluation employs the same locations as those measured in the actual monitoring system.

The first representation of Fig. 12 shows, in the bi-logarithmic plane, the relationship between the (average) spectral acceleration of each stripe and the decrease of frequency, associated with the global damage grade $\widehat{\mathrm{DG}}$. As expected, increasing intensities of the seismic event produce increasing levels of damage and greater frequency reductions, up to the total collapse of the structure (Table 5). States of damage circled in red, in particular, are those exhibiting a soft-storey mechanism (Sect. 3.3) and/or violating the aforementioned MAC criterion. They are thus excluded from the following analyses.

The decrease of frequency as a function of the maximum exhibited interstorey drift is reported in Fig. 13, in the semi-logarithmic plane. Indeed, the relative frequency variations are always negative, as expected, according to a reduction in global stiffness due to structural damage, and their magnitude tends to increase nonlinearly with the maximum response. The frequency reduction appears slightly overestimated, if compared to the one experimentally identified (Sect. 4.4). As physically expected, the relationship follows an initial horizontal slope such that, for very low drifts-thus for negligible damage - no frequency reduction occurs. Even though for the $\mathrm{T}_{y}$ mode the no-reduction interval is wider, reaching drifts up to $2 \times 10^{-4}$, the initial frequency decrease appears to be more rapid. The behaviour in the two directions is quite similar for mid-to-high drifts, even though the frequency decrease for the $T_{x}$ mode seems more regular. After an intermediate "plateau", in which frequencies vary slowly, both the modes encounter a phase of repentine and huge frequency reduction. This behaviour reflects the intuitive expectations, observing that this behaviour pertains to the drift range of complete capacity loss (see the pushover curves of Fig. 3).

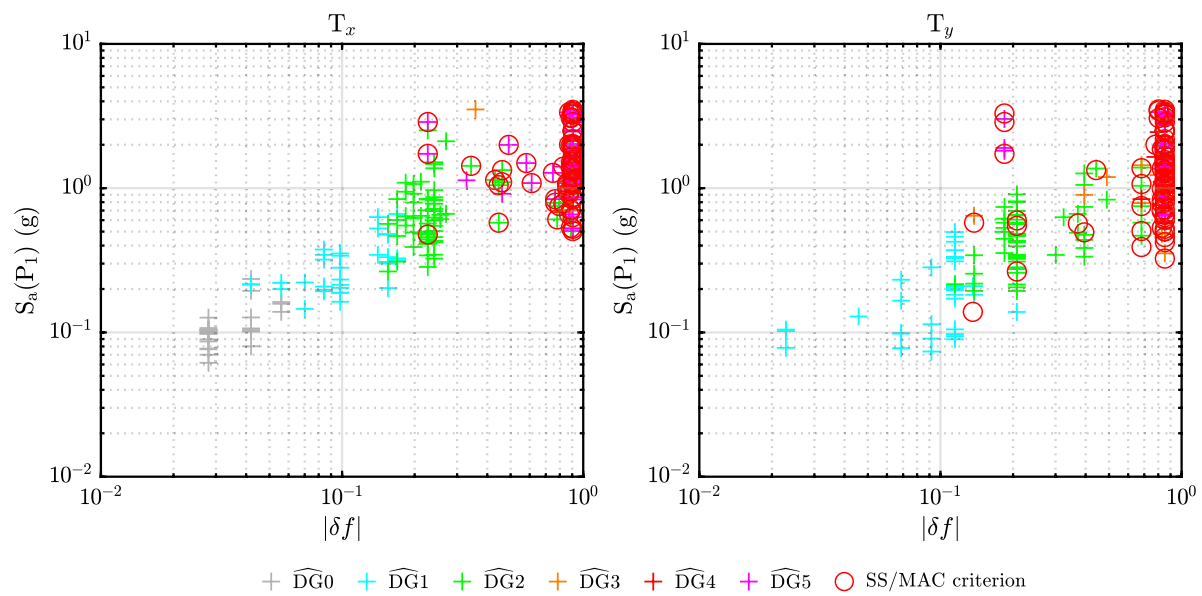

Fig. 12 Post-seismic frequency reduction $\delta f$ of the two first-order bending modes $\mathrm{T}_{x}$ and $\mathrm{T}_{y}$ for stripes of seismic inputs with increasing spectral acceleration $\mathrm{S}_{\mathrm{a}}\left(\mathrm{P}_{1}\right)$, as pseudo-experimentally identified from nonlinear dynamic analyses on the EF model of the Pizzoli town hall building. Colours refer to the global damage grade $\widehat{\mathrm{DG}}$, assigned according to the evaluation procedure of Sect. 3.3 

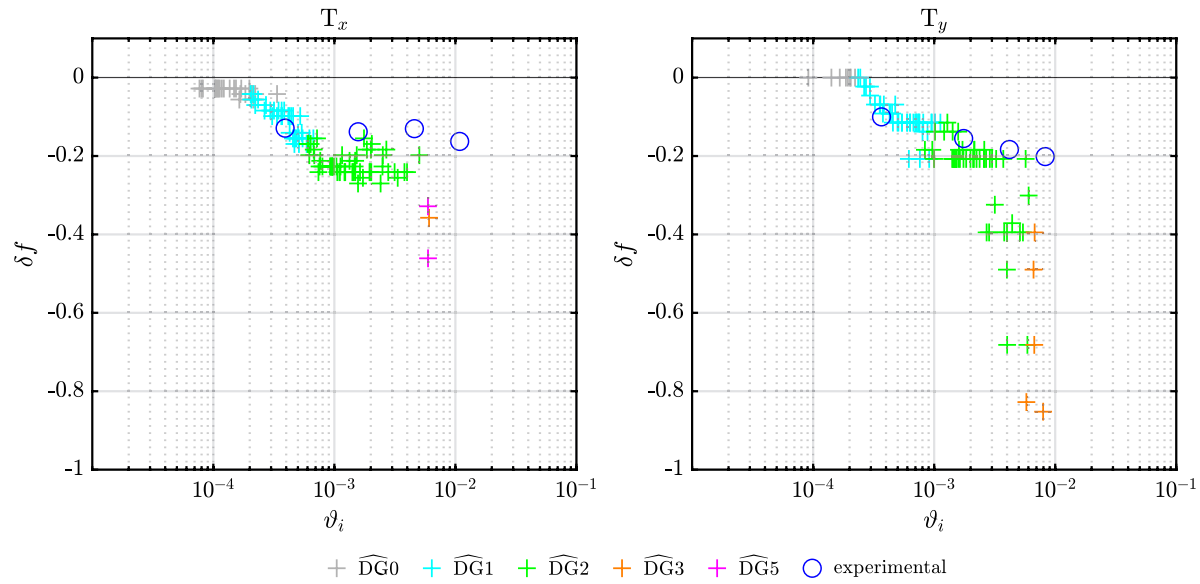

Fig. 13 Frequency decrease $\delta f$ as a function of the maximum interstorey drift $\theta_{i}$, compared to experimental results (Sect. 4.4)

Considering only damage states which respect the mode shape criterion and avoid the soft-storey mechanisms leads to very few samples exhibiting a damage grade $\widehat{\mathrm{DG}} 3$ or higher, so that their statistical characterization in the seismic chart becomes pointless. From a practical perspective, nevertheless, the employment of experimentally based control charts appears more relevant to discriminate between states of slight damage, rather than to identify the occurrence of high damage - which could be easily determined by in situ observations as well. Furthermore, the cases of low-to-medium damage are those in which, following the building inspection, it may be more difficult to correctly judge the practicability of the structure and its response to aftershocks. In this respect, being known the relationship with the residual load-bearing capacity to horizontal actions as well as plausible damage scenarios, the proposed chart could provide useful support to the damage interpretation carried on the field.

Being known an estimate of the post-seismic frequency decrease $\delta f$ for the first-order bending modes, as well as having established a one-to-one association with the global damage grade DG, it is possible to finally build the frequency reduction-damage seismic chart of the building. This representation, conceived as a tool supporting the decisional process regarding the damage state of the building in the post-earthquake scenario, associates the measured physical quantities coming from experimental data-in this case, frequency reductions - to the resulting grade of expected global damage. If a permanent decrease of frequency is identified after the seismic event, the seismic chart provides a rough but quick estimation of the structural damage level to be expected on the structure, both in terms of seriousness and extension according to the EMS-98 provisions.

Assuming the (absolute value of) frequency reduction to be lognormally distributed (Table 7), a commonly adopted strategy in the elaboration of fragility curves (Baraschino et al. 2020), the cumulative distribution function can be interpreted as the probability that a certain damage state is reached or exceeded, being known the decrease of frequency from measurements. This representation forms the proposed frequency reduction-damage seismic chart of the building (Fig. 14). If a permanent reduction in the fundamental frequency of the bending modes is detected after the earthquake, the chart provides a probabilistic expectation of the global damage grade of the building in the corresponding direction. It is understood that, 
Table 7 Mean $m$ and variance $v$ of the lognormal distribution of post-seismic fundamental frequency variations $|\delta f|$, for each of the global damage grades $\widehat{\mathrm{DG}}$

\begin{tabular}{|c|c|c|c|c|c|c|}
\hline & \multicolumn{3}{|l|}{$\left|\delta f_{\mathrm{T}_{x}}\right|$} & \multicolumn{3}{|l|}{$\left|\delta f_{\mathrm{T}_{y}}\right|$} \\
\hline & Samples & $m$ & $v$ & Samples & $m$ & $v$ \\
\hline$\widehat{\mathrm{DG} 0}$ & 27 & 0.0346 & 0.0001 & 0 & - & - \\
\hline$\widehat{\mathrm{DG}} 1$ & 35 & 0.1122 & 0.0021 & 41 & 0.1095 & 0.0034 \\
\hline$\widehat{\mathrm{DG}} 2$ & 57 & 0.2208 & 0.0009 & 50 & 0.2491 & 0.0099 \\
\hline$\geq \widehat{\mathrm{DG}} 3$ & 3 & 0.3842 & 0.0047 & 5 & 0.6581 & 0.0519 \\
\hline
\end{tabular}
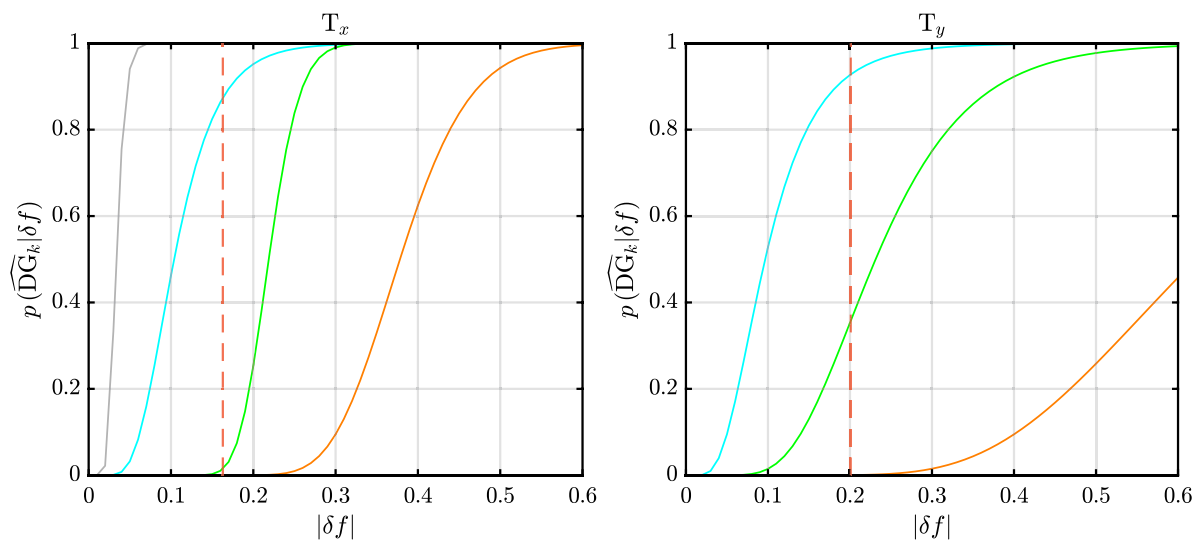

Fig. 14 Equivalent frame-based frequency reduction-damage seismic chart of the Pizzoli town hall building. The figure exemplifies the assessment of the expected damage after the seismic event of 30 October 2017, employing the frequency reduction experimentally identified after the earthquake

given the assumptions underlying the proposal (Sect. 3.1), the frequency decrease should be (i) resulting from structural damage only and (ii) identified checking the invariance of the corresponding mode shape (MAC $\geq 0.8$ ). The first point implies that any other factor that could influence natural frequencies — such as ambient effects, phenomena of recovery, soil-structure interactions etc.- -is modelled (Sect. 4.2) or ruled out a priori.

A simple validation of the chart is pursued indirectly, based on the frequency reduction identified on the structure after the seismic event of 30 October 2017 (Fig. 14). The chart provides a high probability expectation for slight damage, i.e. damage grade $\widehat{\mathrm{DG}} 1$ and a more contained probability (less than $40 \%$ in both directions) to reach a moderate damage state $\widehat{\mathrm{DG}} 2$ along the $y$ direction, in plausible accordance with the actual severity and extension of structural damage observed on the building (Sect. 4.3). 


\section{Conclusions}

The paper proposes a methodological upgrade in the seismic structural health monitoring of strategic masonry buildings, aimed at consistently integrating experimental vibration measurements, on the one side, and efficient computational simulations, on the other side. This primary goal is achieved by exploiting the synthetic Equivalent Frame (EF) formulation to quantify, through nonlinear numerical simulations of the global seismic response, the variations of modal properties for increasing levels of structural damage. The outlined procedure allows the consistent elaboration of a characteristic behavioural chart (seismic chart) of the building, defined on a suited statistical base and relating the seismic damage to the natural frequency reduction. The seismic damage is quantitatively estimated according to the EMS-98 global damage grade, while the decrease of frequency is pseudoexperimentally identified from the simulated post-earthquake ambient response. From the operational viewpoint, the seismic chart can be regarded as a model-driven tool relating an experimentally detected reduction of natural frequencies to the theoretical probability of occurrence of a certain level of damage. Consequently, the seismic chart may provide valuable support for the quick structural health assessment in the general framework of decision-making processes regarding the safety evaluation of damaged buildings in the post-earthquake emergency scenario. The methodology is exemplified for a strategic building permanently monitored by the Italian OSS. The calibrated EF model of the structure is employed to efficiently solve several nonlinear dynamic analyses in a Multiple Stripe Analysis framework, exploring states of damage up to the total collapse of the building. The seismic chart of the building is then developed and validated employing the frequency reductions and damage levels experimentally observed during the 2016-2017 Central Italy earthquake sequence, showing its potential as a quick vibration-based damage estimator. The procedural limitations linked to the effects of environmental variations and frequencyrecovery are briefly discussed and remain to be deepened in future developments of the research. Even though referred to a particular benchmark case, the experimental outcomes suggest monitoring periods longer than those commonly adopted, particularly in the postearthquake phase, to reliably treat the aforementioned phenomena in the frequency-based damage estimation framework. Measurements of ambient and seismic structural vibrations, moreover, can mitigate the influence of aleatory uncertainties commonly affecting the definition of the structural model and the simulation of the response to the earthquake- such as those related to the mechanical properties of building materials. Concerning simulations, some simplifying modelling assumptions adopted in this work-neglecting the damaging of diaphragms and nonstructural elements and the activation of out-of-plane local mechanisms - will be overcome to generalize the tools developed. Nonetheless, the methodology proposed in the paper and exemplified by the use of EF models can be easily pursued with other modelling approaches, shedding some light on the aforementioned problems. Finally, the selection of a suited set of earthquake ground-motion records constitutes another important task to achieve efficient and reliable simulations, suggesting the need for seismic hazard studies at the site on a case by case basis. In this respect, the growth of seismic microzonation activities in medium-to-high seismicity areas, promoted by national civil protection departments, ensures the availability of precious data to support these investigations. The actual possibility of defining the seismic chart in peacetime within a fully virtual simulation environment paves the way for including this structural information in the digital signature of the building, thus enriching its identity card within the emerging Digital Twin concept for structural health monitoring and maintenance. 
Acknowledgements The results presented in this paper are obtained with the partial funding of the ReLUIS Project 2019-2021 (Work Package 6). The authors acknowledge the Italian Department of Civil Protection, in particular the "Osservatorio Sismico delle Strutture" (OSS) in the person of Daniele Spina, for sharing the vibration data acquired from the dynamic monitoring system of the Pizzoli town hall. The authors acknowledge the Italian "Centro Funzionale e Ufficio Idrografico Regione Abruzzo" as well, for providing the environmental measurements of temperature, humidity and rainfall recorded by the weather stations of Pizzoli and L'Aquila. Finally, the authors express their gratitude to Giovanni Fabbrocino and Philippe Guéguen for their precious suggestions aimed at the future developments of this research.

Author contributions DS: methodology, formal analysis, data curation, visualization, writing-original draft. SC: conceptualization, funding acquisition, software, supervision, writing-review \& editing. ML: conceptualization, supervision, writing-review \& editing.

Funding The authors have not disclosed any funding.

\section{Declarations}

Conflict of interest The authors declare that they have no conflict of interest.

Open Access This article is licensed under a Creative Commons Attribution 4.0 International License, which permits use, sharing, adaptation, distribution and reproduction in any medium or format, as long as you give appropriate credit to the original author(s) and the source, provide a link to the Creative Commons licence, and indicate if changes were made. The images or other third party material in this article are included in the article's Creative Commons licence, unless indicated otherwise in a credit line to the material. If material is not included in the article's Creative Commons licence and your intended use is not permitted by statutory regulation or exceeds the permitted use, you will need to obtain permission directly from the copyright holder. To view a copy of this licence, visit http://creativecommons.org/licenses/by/4.0/.

\section{References}

Acunzo G, Fiorini N, Spina D, Dolce M (2022) Application of genetic algorithms for a new approach for seismic building monitoring: integrated measurement systems with physical and virtual sensors. Bull Earthq Eng. https://doi.org/10.1007/s10518-021-01300-z

Allemang RJ (2003) The modal assurance criterion-twenty years of use and abuse. Sound Vib 37(8):14-23

Angiolilli M, Lagomarsino S, Cattari S, Degli Abbati S (2021) Seismic fragility assessment of existing masonry buildings in aggregate. Eng Struct 247:113218

Astorga A, Guéguen P (2020a) Influence of seismic strain rates on the co-and post-seismic response of civil engineering buildings. Earthq Eng Struct Dyn 49(15):1758-1764

Astorga A, Guéguen P (2020b) Structural health building response induced by earthquakes: material softening and recovery. Eng Rep 2(9):e12228

Astorga A, Guéguen P, Kashima T (2018) Nonlinear elasticity observed in buildings during a long sequence of earthquakes. Bul Seismol Soc Am 108(3A):1185-1198

Astorga AL, Guéguen P, Riviere J, Kashima T, Johnson PA (2019) Recovery of the resonance frequency of buildings following strong seismic deformation as a proxy for structural health. Struct Health Monit 18(5-6):1966-1981

Baraschino R, Baltzopoulos G, Iervolino I (2020) R2R-EU: software for fragility fitting and evaluation of estimation uncertainty in seismic risk analysis. Soil Dyn Earthq Eng 132:106093

Bazzurro P, Cornell CA, Shome N, Carballo JE (1998) Three proposals for characterizing MDOF nonlinear seismic response. J Struct Eng 124(11):1281-1289

Beyer K, Mangalathu S (2013) Review of strength models for masonry spandrels. Bull Earthq Eng 11(2):521-542

Bodin P, Vidale J, Walsh T, Çakir R, Çelebi M (2012) Transient and long-term changes in seismic response of the natural resources building, Olympia, Washington, due to earthquake shaking. J Earthq Eng 16(5):607-622

Boschi S, Bernardini C, Vignoli A (2021) The Tuscany Masonry database website. Heritage 4(1):230-248 
Brincker R, Zhang L, Andersen P (2001) Modal identification of output-only systems using frequency domain decomposition. Smart Mater Struct 10(3):441

Brownjohn JM, De Stefano A, Xu YL, Wenzel H, Aktan AE (2011) Vibration-based monitoring of civil infrastructure: challenges and successes. J Civ Struct Health Monit 1(3):79-95

Brunelli A, de Silva F, Piro A, Parisi F, Sica S, Silvestri F, Cattari S (2021) Numerical simulation of the seismic response and soil-structure interaction for a monitored masonry school building damaged by the 2016 Central Italy earthquake. Bull Earthq Eng 19(2):1181-1211

Cabboi A, Gentile C, Saisi A (2017) From continuous vibration monitoring to FEM-based damage assessment: application on a stone-masonry tower. Constr Build Mater 156:252-265

Calderini C, Cattari S, Lagomarsino S (2009) In-plane strength of unreinforced masonry piers. Earthq Eng Struct Dyn 38(2):243-267

Carden EP, Fanning P (2004) Vibration based condition monitoring: a review. Struct Health Monit 3(4):355-377

Cattari S, Angiolilli M (2022) Procedure for the attribution of EMS98-damage levels in masonry buildings from observed seismic damage or nonlinear analyses. Bull Earthq Eng (Under review)

Cattari S, Lagomarsino S (2013) Masonry structures. In: Developments in the field of displacement based seismic assessment, IUSS Press and EUCENTRE, pp 151-200

Cattari S, Camilletti D, Lagomarsino S, Bracchi S, Rota M, Penna A (2018) Masonry Italian codeconforming buildings. Part 2: nonlinear modelling and time-history analysis. J Earthq Eng 22(sup2):2010-2040

Cattari S, Degli Abbati S, Ottonelli D, Marano C, Camata G, Spacone E, Da Porto F, Modena C, Lorenzoni F, Magenes G, Penna A, Graziotti F, Ceravolo R, Miraglia G, Lenticchia E, Fiorini N, Spina D (2019) Discussion on data recorded by the Italian structural seismic monitoring network on three masonry structures hit by the 2016-2017 Central Italy earthquake. In: Proceedings of the 7th International Conference on Computational Methods in Structural Dynamics and Earthquake Engineering (COMPDYN 2019), Crete, Greece

Cattari S, Camilletti D, D'Altri AM, Lagomarsino S (2021a) On the use of continuum Finite Element and Equivalent Frame models for the seismic assessment of masonry walls. J Build Eng 43:102519

Cattari S, Degli Abbati S, Alfano S, Brunelli A, Lorenzoni F, da Porto F (2021b) Dynamic calibration and seismic validation of numerical models of URM buildings through permanent monitoring data. Earthq Eng Struct Dyn

Çelebi M (2007) On the variation of fundamental frequency (period) of an undamaged building-a continuing discussion. In: Proceedings of the International Conference on Experimental Vibration Analysis for Civil Engineering Structures, Porto, Portugal

Ceravolo R, Matta E, Quattrone A, Zanotti Fragonara L (2017) Amplitude dependence of equivalent modal parameters in monitored buildings during earthquake swarms. Earthq Eng Struct Dyn 46(14):2399-2417

Ceravolo R, Lenticchia E, Miraglia G (2018) Use of spectral entropy for damage detection in masonry buildings in the presence of mild seismicity. Proceedings 2(8):432

Clinton JF, Bradford SC, Heaton TH, Favela J (2006) The observed wander of the natural frequencies in a structure. Bull Seismol Soc Am 96(1):237-257

De Sortis A, Antonacci E, Vestroni F (2005) Dynamic identification of a masonry building using forced vibration tests. Eng Struct 27(2):155-165

Degli Abbati S, Morandi P, Cattari S, Spacone E (2021) On the reliability of the equivalent frame models: the case study of the permanently monitored Pizzoli's town hall. Bull Earthq Eng: 1-31

Di Ludovico M, De Martino G, Santoro A, Prota A, Manfredi G, Calderini C, Carocci C, Da Porto F, Dall'Asta A, De Santis S et al (2019a) Usability and damage assessment of public buildings and churches after the 2016 Central Italy earthquake: the ReLUIS Experience. In: 7th International Conference on Earthquake Geotechnical Engineering (ICEGE 2019). Italy, Rome, pp 915-924

Di Ludovico M, Digrisolo A, Moroni C, Graziotti F, Manfredi V, Prota A, Dolce M, Manfredi G (2019b) Remarks on damage and response of school buildings after the Central Italy earthquake sequence. Bull Earthq Eng 17(10):5679-5700

Di Ludovico M, Santoro A, De Martino G, Moroni C, Prota A, Dolce M, Manfredi G (2019c) Cumulative damage to school buildings following the 2016 Central Italy earthquake sequence. Bollettino di Geofisica Teorica ed Applicata 60(2)

Di Ludovico M, De Martino G, Prota A, Manfredi G, Dolce M (2021) Damage assessment in Italy, and experiences after recent earthquakes on reparability and repair costs. In: Advances in assessment and modeling of earthquake loss. Springer, pp 65-84 
Doebling SW, Farrar CR, Prime MB, Shevitz DW (1996) Damage identification and health monitoring of structural and mechanical systems from changes in their vibration characteristics: a literature review. Tech. rep., Los Alamos National Lab., NM (United States)

Doebling SW, Farrar CR, Prime MB et al (1998) A summary review of vibration-based damage identification methods. Shock Vib Digest 30(2):91-105

Dolce M, Di Bucci D (2014) National Civil Protection Organization and technical activities in the 2012 Emilia earthquakes (Italy). Bull Earthq Eng 12(5):2231-2253

Dolce M, Nicoletti M, De Sortis A, Marchesini S, Spina D, Talanas F (2017a) Osservatorio sismico delle strutture: the Italian structural seismic monitoring network. Bull Earthq Eng 15(2):621-641

Dolce M, Speranza E, Giordano F, Borzi B, Bocchi F (2017b) Da. DO-A web-based tool for analyzing and comparing post-earthquake damage database relevant to national seismic events since 1976. In: Proceedings of the XVII ANIDIS conference, L'Aquila, Italy

Dolce M, Speranza E, Bocchi F, Conte C (2019a) Structural operational efficiency indices for Emergency Limit Condition (I. OPà. CLE): experimental results. Bollettino di Geofisica Teorica ed Applicata 60(2)

Dolce M, Speranza E, Giordano F, Borzi B, Bocchi F, Conte C, Di Meo A, Faravelli M, Pascale V (2019b) Observed damage database of past Italian earthquakes: the Da. DO WebGIS. Bollettino di Geofisica Teorica ed Applicata 60(2)

D’Altri AM, Sarhosis V, Milani G, Rots J, Cattari S, Lagomarsino S, Sacco E, Tralli A, Castellazzi G, de Miranda S (2020) Modeling strategies for the computational analysis of unreinforced masonry structures: review and classification. Arch Comput Methods Eng 27(4):1153-1185

European Committee for Standardization (CEN) (2004) Eurocode 8: Design of structures for earthquake resistance-Part 1: general rules, seismic actions and rules for buildings (EN 1998-1). Tech. rep

Ewins DJ (2016) Exciting vibrations: the role of testing in an era of supercomputers and uncertainties. Meccanica 51(12):3241-3258

Farrar CR, Doebling SW, Nix DA (2001) Vibration-based structural damage identification. Philos Trans R Soc Lond A Math Phys Eng Sci 359(1778):131-149

Feng D, Feng MQ (2018) Computer vision for SHM of civil infrastructure: from dynamic response measurement to damage detection-a review. Eng Struct 156:105-117

Foti D, Gattulli V, Potenza F (2014) Output-only identification and model updating by dynamic testing in unfavorable conditions of a seismically damaged building. Comput-Aided Civ Infrastruct Eng 29(9):659-675

García-Macías E, Ubertini F (2020) MOVA/MOSS: two integrated software solutions for comprehensive Structural Health Monitoring of structures. Mech Syst Signal Process 143:106830

García-Macías E, Venanzi I, Ubertini F (2020) Metamodel-based pattern recognition approach for realtime identification of earthquake-induced damage in historic masonry structures. Autom Constr 120:103389

Gattulli V, Lepidi M, Potenza F (2016) Dynamic testing and health monitoring of historic and modern civil structures in Italy. Struct Monit Maintenance 3(1):71-90

Gentile C, Saisi A (2007) Ambient vibration testing of historic masonry towers for structural identification and damage assessment. Constr Build Mater 21(6):1311-1321

Giovinazzi S, Lagomarsino S (2004) A macroseismic method for the vulnerability assessment of buildings. In: Proceedings of the 13th World Conference on Earthquake Engineering (WCEE), Vancouver, Canada

Grünthal G (1998) European macroseismic scale 1998. Tech. rep, European Seismological Commission (ESC)

Guéguen P, Gallipoli MR, Navarro M, Masi A, Michel C, Guillier B, Karakostas C, Lekidis V, Mucciarelli M, Ponzo F, et al. (2014) Testing buildings using ambient vibrations for earthquake engineering: a European review. In: Proceedings of the 2nd European Conference on Earthquake Engineering and Seismology (2ECEES), Istanbul, Turkey

Guéguen P, Brossault MA, Roux P, Singaucho JC (2020) Slow dynamics process observed in civil engineering structures to detect structural heterogeneities. Eng Struct 202:109833

Iervolino I, Dolce M (2018) Foreword to the special issue for the RINTC (the implicit seismic risk of code-conforming structures) project. J Earthq Eng 22(2):1-4

Iervolino I, Galasso C, Cosenza E (2010) REXEL: computer aided record selection for code-based seismic structural analysis. Bull Earthq Eng 8(2):339-362

Iervolino I, Chioccarelli E, Convertito V (2011) Engineering design earthquakes from multimodal hazard disaggregation. Soil Dyn Earthq Eng 31(9):1212-1231

Iervolino I, Spillatura A, Bazzurro P (2018) Seismic reliability of code-conforming Italian buildings. J Earthq Eng 22(sup2):5-27 
Italian Ministry of Infrastructures and Transportation (MIT) (2019) Istruzioni per l'applicazione dell' «Aggiornamento delle "Norme tecniche per le costruzioni"» di cui al decreto ministeriale 17 gennaio 2018 (Circular 21/1/19, No. 7 C.S.LL.PP). Tech. rep., Rome, Italy (in Italian)

Jalayer F, Cornell C (2009) Alternative non-linear demand estimation methods for probability-based seismic assessments. Earthq Eng Struct Dyn 38(8):951-972

Jalayer F, De Risi R, Manfredi G (2015) Bayesian Cloud Analysis: efficient structural fragility assessment using linear regression. Bull Earthq Eng 13(4):1183-1203

Jalayer F, Ebrahimian H, Miano A, Manfredi G, Sezen H (2017) Analytical fragility assessment using unscaled ground motion records. Earthq Eng Struct Dyn 46(15):2639-2663

Kita A, Cavalagli N, Masciotta MG, Lourenço PB, Ubertini F (2020) Rapid post-earthquake damage localization and quantification in masonry structures through multidimensional non-linear seismic IDA. Eng Struct 219:110841

Kita A, Cavalagli N, Venanzi I, Ubertini F (2021) A new method for earthquake-induced damage identification in historic masonry towers combining OMA and IDA. Bull Earthq Eng 19(12):5307-5337

Kouris LAS, Penna A, Magenes G (2019) Dynamic modification and damage propagation of a two-storey full-scale masonry building. Adv Civ Eng 2019

Kržan M, Gostič S, Cattari S, Bosiljkov V (2015) Acquiring reference parameters of masonry for the structural performance analysis of historical buildings. Bull Earthq Eng 13(1):203-236

Lagomarsino S, Cattari S (2015) Perpetuate guidelines for seismic performance-based assessment of cultural heritage masonry structures. Bull Earthq Eng 13(1):13-47

Lagomarsino S, Cattari S (2015) Seismic performance of historical masonry structures through pushover and nonlinear dynamic analyses. In: Perspectives on European earthquake engineering and seismology. Springer, Cham, pp 265-292

Lagomarsino S, Giovinazzi S (2006) Macroseismic and mechanical models for the vulnerability and damage assessment of current buildings. Bull Earthq Eng 4(4):415-443

Lagomarsino S, Penna A, Galasco A, Cattari S (2013) Tremuri program: an equivalent frame model for the nonlinear seismic analysis of masonry buildings. Eng Struct 56:1787-1799

Lagomarsino S, Cattari S, Ottonelli D (2021) The heuristic vulnerability model: fragility curves for masonry buildings. Bull Earthq Eng 19(8):3129-3163

Limongelli MP, Çelebi M (2019) Seismic structural health monitoring: from theory to successful applications. Springer

Luş H, Betti R, Longman RW (1999) Identification of linear structural systems using earthquake-induced vibration data. Earthq Eng Struct Dyn 28(11):1449-1467

Luzi G, Crosetto M, Fernández E (2017) Radar interferometry for monitoring the vibration characteristics of buildings and civil structures: recent case studies in spain. Sensors 17(4):669

Marino S, Cattari S, Lagomarsino S (2019) Are the nonlinear static procedures feasible for the seismic assessment of irregular existing masonry buildings? Eng Struct 200:109700

Martakis P, Reuland Y, Chatzi E (2021) Amplitude-dependent model updating of masonry buildings undergoing demolition. Smart Struct Syst 27(2):157-172

Michel C, Guéguen P (2010) Time-frequency analysis of small frequency variations in civil engineering structures under weak and strong motions using a reassignment method. Struct Health Monit 9(2):159-171

Michel C, Guéguen P, Bard PY (2008) Dynamic parameters of structures extracted from ambient vibration measurements: an aid for the seismic vulnerability assessment of existing buildings in moderate seismic hazard regions. Soil Dyn Earthq Eng 28(8):593-604

Michel C, Zapico B, Lestuzzi P, Molina FJ, Weber F (2011) Quantification of fundamental frequency drop for unreinforced masonry buildings from dynamic tests. Earthq Eng Struct Dyn 40(11):1283-1296

Miraglia G, Lenticchia E, Surace C, Ceravolo R (2020) Seismic damage identification by fitting the nonlinear and hysteretic dynamic response of monitored buildings. J Civ Struct Health Monit 10(3):457-469

Morandi P, Albanesi L, Graziotti F, Piani TL, Penna A, Magenes G (2018) Development of a dataset on the in-plane experimental response of URM piers with bricks and blocks. Constr Build Mater 190:593-611

Morassi A, Vestroni F (2008) Dynamic methods for damage detection in structures. Springer

Mottershead JE, Friswell M (1993) Model updating in structural dynamics: a survey. J Sound Vib 167(2):347-375

Mouyiannou A, Rota M, Penna A, Magenes G (2014) Identification of suitable limit states from nonlinear dynamic analyses of masonry structures. J Earthq Eng 18(2):231-263

Ottonelli D, Cattari S, Lagomarsino S (2020) Displacement-based simplified seismic loss assessment of masonry buildings. J Earthq Eng 24(sup1):23-59 
Picozzi M, Ditommaso R, Parolai S, Mucciarelli M, Milkereit C, Sobiesiak M, Di Giacomo D, Gallipoli M, Pilz M, Vona M et al (2010) Real time monitoring of structures in task force missions: the example of the $\mathrm{Mw}=6.3$ Central Italy Earthquake, April 6, 2009. Nat Hazards 52(2):253-256

Ponte M, Bento R, Vaz SD (2021) A multi-disciplinary approach to the seismic assessment of the National Palace of Sintra. Int J Archit Heritage 15(5):757-778

Ponzo FC, Ditommaso R, Auletta G, Mossucca A (2010) A fast method for structural health monitoring of Italian reinforced concrete strategic buildings. Bull Earthq Eng 8(6):1421-1434

Reuland Y, Lestuzzi P, Smith IF (2019) Measurement-based support for post-earthquake assessment of buildings. Struct Infrastruct Eng 15(5):647-662

Reynders E (2012) System identification methods for (operational) modal analysis: review and comparison. Arch Comput Methods Eng 19(1):51-124

Rezaie A, Achanta R, Godio M, Beyer K (2020) Comparison of crack segmentation using digital image correlation measurements and deep learning. Constr Build Mater 261:120474

Rezaie A, Godio M, Beyer K (2020) Experimental investigation of strength, stiffness and drift capacity of rubble stone masonry walls. Constr Build Mater 251:118972

Ricci P, Manfredi V, Noto F, Terrenzi M, Petrone C, Celano F, De Risi MT, Camata G, Franchin P, Magliulo $\mathrm{G}$ et al (2018) Modeling and seismic response analysis of Italian code-conforming reinforced concrete buildings. J Earthq Eng 22(sup2):105-139

RINTC Workgroup (2018) Results of the 2015-2017 implicit seismic risk of code-conforming structures in Italy (RINTC) project. ReLUIS report, Rete dei Laboratori Universitari di Ingegneria Sismica (ReLUIS), Naples, Italy

Rosti A, Rota M, Penna A (2020) Empirical fragility curves for Italian URM buildings. Bull Earthq Eng 19:3057-3076

Rota M, Penna A, Strobbia C (2008) Processing Italian damage data to derive typological fragility curves. Soil Dyn Earthq Eng 28(10-11):933-947

Saisi A, Gentile C, Guidobaldi M (2015) Post-earthquake continuous dynamic monitoring of the Gabbia Tower in Mantua, Italy. Constr Build Mater 81:101-112

Salawu O (1997) Detection of structural damage through changes in frequency: a review. Eng Struct 19(9):718-723

Sextos A, De Risi R, Pagliaroli A, Foti S, Passeri F, Ausilio E, Cairo R, Capatti MC, Chiabrando F, Chiaradonna A et al (2018) Local site effects and incremental damage of buildings during the 2016 Central Italy earthquake sequence. Earthq Spectra 34(4):1639-1669

Sivori D, Lepidi M, Cattari S (2020) Ambient vibration tools to validate the rigid diaphragm assumption in the seismic assessment of buildings. Earthq Eng Struct Dyn 49(2):194-211

Sivori D, Lepidi M, Cattari S (2021) Structural identification of the dynamic behavior of floor diaphragms in existing buildings. Smart Struct Syst 27(2):173-191

Snoj J, Österreicher M, Dolšek M (2013) The importance of ambient and forced vibration measurements for the results of seismic performance assessment of buildings obtained by using a simplified non-linear procedure: case study of an old masonry building. Bull Earthq Eng 11(6):2105-2132

Spina D, Lamonaca B (1998) Strengthening assessment of building using ambient vibration tests. In: Proceedings of the 11th European Conference on Earthquake Engineering, Paris, France

Spina D, Lamonaca B, Nicoletti M, Dolce M (2011) Structural monitoring by the Italian Department of Civil Protection and the case of 2009 Abruzzo seismic sequence. Bull Earthq Eng 9(1):325-346

Spina D, Acunzo G, Fiorini N, Mori F, Dolce M (2019) A probabilistic simplified seismic model of masonry buildings based on ambient vibrations. Bull Earthq Eng 17(2):985-1007

Spina D, Acunzo G, Fiorini N, Mori F, Dolce M (2021) A probabilistic simplified Seismic Model from Ambient Vibrations (SMAV) of existing reinforced concrete buildings. Eng Struct 238:112255

Todorovska MI (2009) Soil-structure system identification of Millikan Library North-South response during four earthquakes (1970-2002): What caused the observed wandering of the system frequencies? Bull Seismol Soc Am 99(2A):626-635

Toti J, Gattulli V, Sacco E (2015) Nonlocal damage propagation in the dynamics of masonry elements. Comput Struct 152:215-227

Ubertini F, Comanducci G, Cavalagli N, Pisello AL, Materazzi AL, Cotana F (2017) Environmental effects on natural frequencies of the San Pietro bell tower in Perugia, Italy, and their removal for structural performance assessment. Mech Syst Signal Process 82:307-322

Vamvatsikos D, Cornell C (2002) Incremental dynamic analysis. Earthq Eng Struct Dyn 31(3):491-514

Vanin F, Zaganelli D, Penna A, Beyer K (2017) Estimates for the stiffness, strength and drift capacity of stone masonry walls based on 123 quasi-static cyclic tests reported in the literature. Bull Earthq Eng 15(12):5435-5479 
Venanzi I, Kita A, Cavalagli N, Ierimonti L, Ubertini F (2020) Earthquake-induced damage localization in an historic masonry tower through long-term dynamic monitoring and FE model calibration. Bull Earthq Eng 18(5):2247-2274

Vidal F, Navarro M, Aranda C, Enomoto T (2014) Changes in dynamic characteristics of Lorca RC buildings from pre-and post-earthquake ambient vibration data. Bull Earthq Eng 12(5):2095-2110

Publisher's Note Springer Nature remains neutral with regard to jurisdictional claims in published maps and institutional affiliations. 